\title{
Thirteen new species and new distribution records of Helicopsyche (Feropsyche) Johanson from Venezuela (Trichoptera: Helicopsychidae)
}

\author{
KJELL ARNE JOHANSON ${ }^{1} \&$ RALPH W. HOLZENTHAL ${ }^{2}$ \\ ${ }^{1}$ Swedish Museum of Natural History, Entomology Department, Box 50007, 10405 Stockholm, Sweden \\ (kjell.arne.johanson@nrm.se) \\ 2 Department of Entomology, University of Minnesota, 1980 Folwell Ave., Room 219, St. Paul, Minnesota, \\ 55108,U.S.A. (holze001@umn.edu)
}

\section{Table of contents}

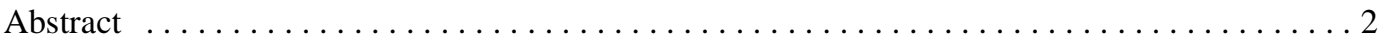

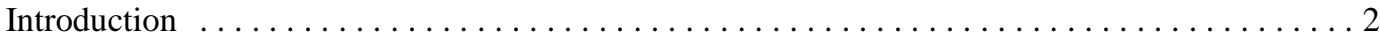

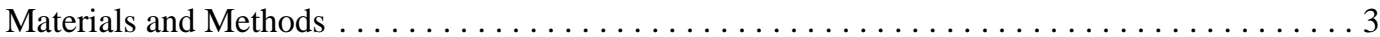

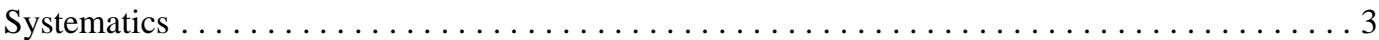

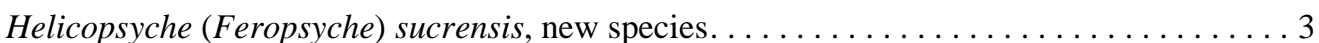

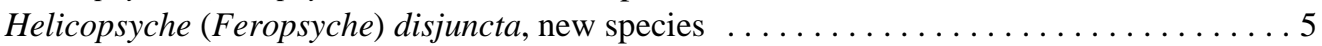

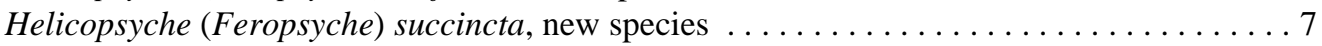

Helicopsyche (Feropsyche) camuriensis, new species $\ldots \ldots \ldots \ldots \ldots \ldots \ldots \ldots$

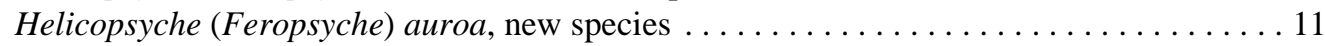

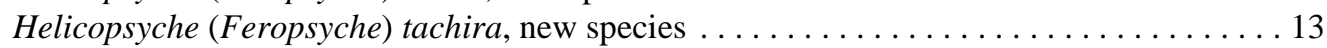

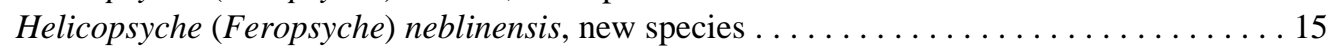

Helicopsyche (Feropsyche) venezuelensis, new species . . . . . . . . . . . . 17

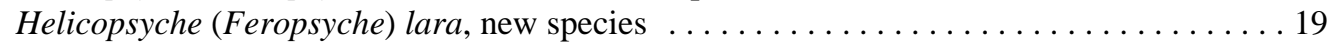

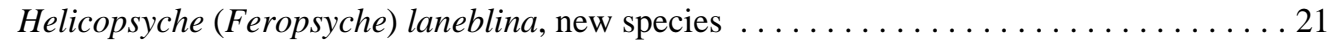

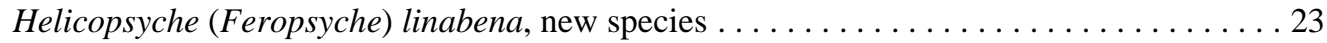

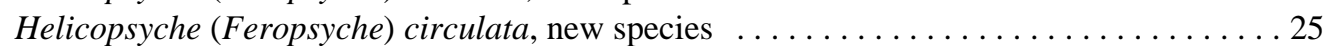

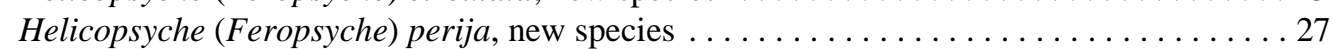

New distribution records of Venezuelan Helicopsyche (Feropsyche $)$. . . . . . . . . . . . . 29

Helicopsyche (Feropsyche) angulata Flint . . . . . . . . . . . . . . . . . . 29

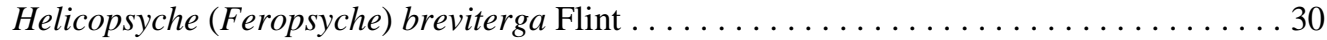

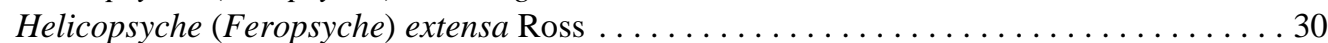

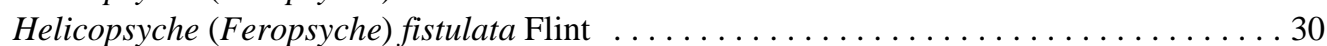

Helicopsyche (Feropsyche) grenadensis Flint \& Sykora . . . . . . . . . . . . 31

Helicopsyche (Feropsyche) maculisternum Botosaneanu ................. 31

Helicopsyche (Feropsyche) merida Botosaneanu \& Flint $\ldots \ldots \ldots \ldots \ldots \ldots \ldots \ldots \ldots$

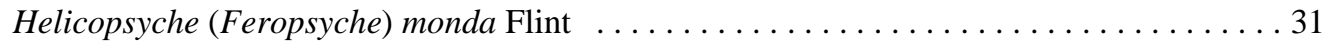

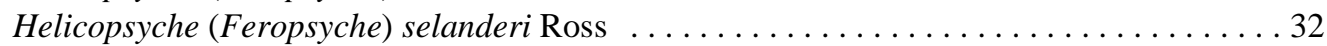




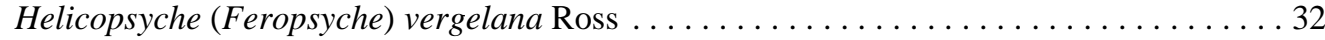

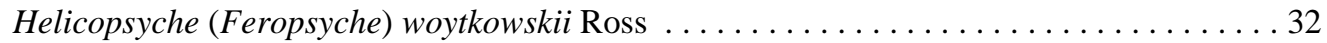

Key to males of Venezuelan Helicopsyche (Feropsyche) $\ldots \ldots \ldots \ldots \ldots \ldots \ldots \ldots \ldots \ldots$

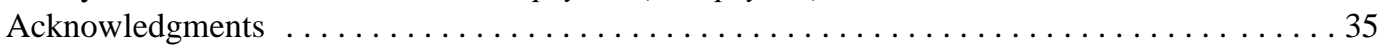

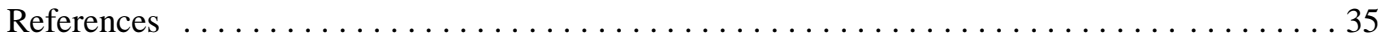

\begin{abstract}
Thirteen new species of Helicopsyche subgenus Feropsyche are described and illustrated from Venezuela: $H$. auroa, new species, $H$. camuriensis, new species, $H$. circulata, new species, $H$. disjuncta, new species, $H$. laneblina, new species, $H$. lara, new species, $H$. linabena, new species, $H$. neblinensis, new species, $H$. perija, new species, $H$. succincta, new species, $H$. sucrensis, new species, $H$. tachira, new species, and $H$. venezuelensis, new species. In addition, new distribution records for Venezuela are reported for $H$. angulata Flint, $H$. breviterga Flint, $H$. extensa Ross, $H$. fistulata Flint, H. grenadensis Flint \& Sykora, H. maculisternum Botosaneanu, H. merida Botosaneanu \& Flint, $H$. monda Flint, $H$. selanderi Ross, $H$. vergelana Ross, and $H$. woytkowskii Ross. Finally, a key to males of the known species in the subgenus from Venezuela is included.
\end{abstract}

Key words: Trichoptera, Helicopsychidae, Helicopsyche, Feropsyche, snail case caddisflies, Neotropics, Venezuela, new species, taxonomy, key.

\title{
Introduction
}

The Venezuelan Trichoptera fauna is composed of approximately 240 described species (Flint et al. 1999, Harris \& Flint 2002, Harris et al. 2002a, b, Johanson 2003a), of which 90\% are included within 6 families: Helicopsychidae (14 spp.), Hydrobiosidae (20 spp.), Hydroptilidae (49 spp.), Hydropsychidae (57 spp.), Leptoceridae (27 spp.), and Philopotamidae (46 spp.). As is commonplace throughout the Neotropics, the known Venezuelan caddisfly fauna undoubtedly represents only a fraction of the true fauna with many undescribed species awaiting discovery and description (e.g., Holzenthal \& Cressa 2003, Blahnik 2004).

American Helicopsychidae, or snail case caddisflies, all belong to the genus Helicopsyche, and are divided into two subgenera: Helicopsyche (Feropsyche) Johanson and Helicopsyche (Cochliopsyche) Müller. With 73 described species (Johanson 2002, 2003a), Feropsyche is the largest subgenus, while Cochliopsyche presently includes 16 species (Johanson 2003b). Adults of the two subgenera are morphologically distinct: in Cochliopsyche the antennae are more than twice the length of the forewing and the hind tibiae lack preapical spurs, in Feropsyche the antennae are less than twice the length of the forewing and the hind tibiae possess 2 preapical spurs (Johanson (1998). Flint et al. (1999) previously recorded 9 Helicopsyche (Feropsyche) from Venezuela: H. angulata Flint (known from Colombia, Ecuador, and Venezuela), H. colombiensis von Siebold 
(Colombia, Venezuela), H. fistulata Flint (Colombia, Venezuela), H. maculisternum Botosaneanu (Trinidad, Venezuela), H. margaritensis Botosaneanu (Grenada, Trinidad, Venezuela), H. merida Botosaneanu \& Flint (Venezuela), H. scalaris Hagen (Venezuela), $H$. thelidomus Hagen (Venezuela), and H. vergelana Ross (widely distributed from Mexico, through Central America, to Brazil, Paraguay, Peru, and Venezuela in South America).

Helicopsyche margaritensis was synonymized with H. vergelana by Johanson (2002) and the species described by Hagen and von Siebold were based on larval cases so their true identity remains unknown (nomina dubia). The current paper includes the description of 13 new species of Helicopsyche from Venezuela as well as new country records for $H$. breviterga Flint (previously known from Colombia), H. extensa Ross (Colombia), H. grenadensis Flint \& Sykora (Grenada), H. monda Flint (Argentina, Brazil, Paraguay), $H$. selanderi Ross (Mexico), and H. woytkowskii Ross (Peru). The number of species in the genus now known from Venezuela is 24 (excluding the nomina dubia), almost tripling the previously recorded diversity.

\section{Materials and Methods}

Techniques and procedures used in the preparation and examination of specimens are those outlined by Blahnik \& Holzenthal (2004) and Holzenthal \& Andersen (2004). Terminology used for morphological structures follows that of Johanson (2002). Type material and other material examined has been deposited in the University of Minnesota Insect Collection, St. Paul, Minnesota, U.S.A. (UMSP), the National Museum of Natural History, Smithsonian Institution, Washington, D.C., U.S.A. (NMNH), the Swedish Museum of Natural History, Stockholm, Sweden (NRM), the Museo del Instituto de Zoología Agrícola, Maracay, Venezuela (IZAM), and the Zoological Museum, University of Amsterdam, The Netherlands (ZMUA).

\section{Systematics}

\section{Helicopsyche (Feropsyche) sucrensis, new species}

Fig. 1-7, 90

In the male genitalia of the new species, the pointed process at the posterodorsal corner of the gonocoxite is longer and more prominent than in the group of similar American Helicopsyche species that includes $H$. apicauda Flint, $H$. flinti Johanson, $H$. grenadensis Flint \& Sykora, H. incisa Ross, H. kalaom Botosanuanu, H. lambda Flint, H. limnella Ross, $H$. merida Botosaneanu \& Flint, H. molesta Botosaneanu, H. monda Flint, H. paucispina Botosaneanu \& Flint, and H. valligera Flint. Helicopsyche sucrensis can also be separated from these species by the anterior and posterior margins of the gonocoxite that run nearly 
parallel. It can be further distinguished from $H$. apicauda, $H$. flinti, $H$. grenadensis, $H$. lambda, and $H$. valligera by the absence of small lobes along the posterior margin of the gonocoxite. Finally, $H$. sucrensis can be separated from $H$. limnella, H. merida, $H$. molesta, H. monda, and $H$. paucispina by the slightly wider anterior lobe of segment IX in lateral view.
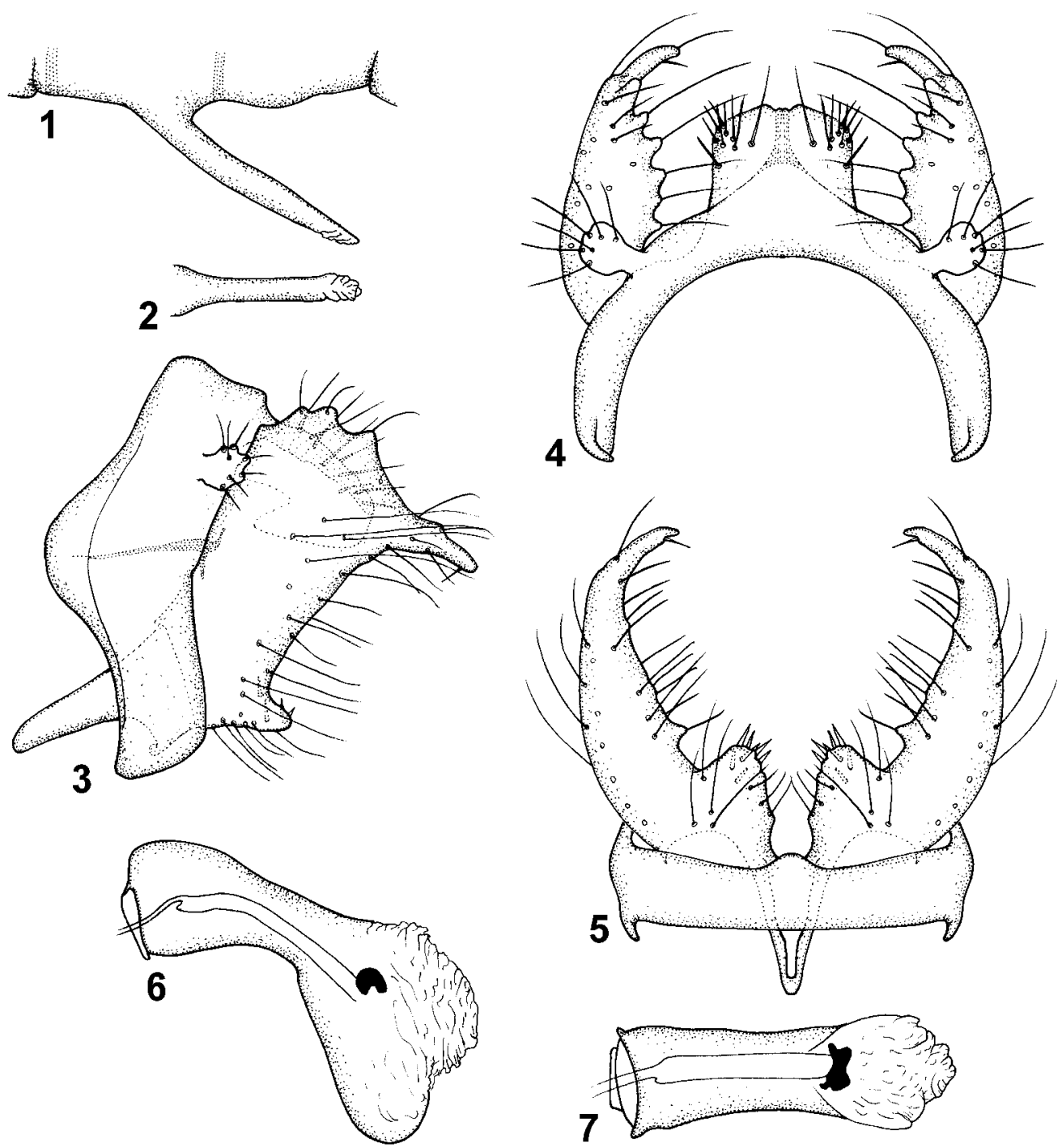

FIGURES 1-7. Helicopsyche sucrensis, new species, holotype. 1-sternum VI process, lateral; 2-sternum VI process, ventral; 3-male genitalia, lateral; 4- male genitalia, dorsal; 5-male genitalia, ventral; 6-phallus, lateral; 7—phallus, ventral.

Male. Head: Antennal scape slightly shorter than eye diameter. Maxillary palp distal segment slightly shorter than proximal segment and scape. Cephalic warts slightly oval, 
about $1 / 2$ as long as eye diameter, with pale grey and dark brown setae. Forewing golden brownish, length $3.3 \mathrm{~mm}$. Sternum VI process (Fig. 1,2) nearly $2 / 3$ its segment length, apparently without microtrichiae; nearly straight in lateral view (Fig. 1), oriented posteroventrally, tubular along its length, except slightly wider at apex; apex lamellate (Fig. 2). Male genitalia (Fig. 3-7). Segment IX, in lateral view (Fig. 3), with anterior lobe ellipsoid, oriented anteriad, present midlaterally; anterodorsal margin slightly concave; anteroventral margin concave; in dorsal view (Fig. 4), with inner margin uniformly ellipsoid; in ventral view (Fig. 5), with posterior process midventrally; lateral apodeme present as horizontal, nearly straight line (Fig. 3), tapering anteriorly, diminishing before meeting anterior margin; sub-marginal line present; tergal transverse apodeme apparently absent; sternal transverse apodeme absent. Segment X, in lateral view (Fig. 3), oriented posteroventrad, nearly straight; dorsally slightly produced; apex truncate; in dorsal view (Fig. 4), parallel along its length, apical part weakly notched; with about 9 pairs of megasetae in lateral group starting midway on segment, the lateral megasetae somewhat shorter than the others. Superior appendage (Fig. 3) strongly club-shaped, oriented posterolaterad. Primary branch of gonocoxite, in lateral view (Fig. 3), generally parallel-sided at midlength, with strongly undulate dorsal margin due to slightly erect setal bases; apex strongly produced posteriorly and curving medially; central part of primary branch slightly wider than height of central part of tergum X (Fig. 3); anterodorsal margin nearly straight, smooth; posteroventral margin without undulations; basimesal lobe visible in lateral view (Fig. 3), wide, rounded in ventral view (Fig. 5), with weakly undulating median margins, smooth; with about 7 megasetae on dorsal surface; basal plate, in lateral view (Fig. 3), nearly straight, wide along its length; in ventral view (Fig. 5), triangular, apex rounded. Phallus, in lateral view (Fig. 6), with anterior half nearly straight, sharply bent ventrad at midlength, dorsal margin weakly undulating; ventral margin strongly angled; anterior 1/4 twice as broad as its central part (Fig. 6); in ventral view (Fig. 7), phallobase present as narrow lobe; endotheca weakly produced; sperm channel divided into thick posterior and slender anterior parts; posteroventral part strongly sclerotized.

Holotype male: VENEZUELA: Sucre: Peninsula de Paria, Puerto Viejo, "Rio el Pozo", $10^{\circ} 43.073^{\prime} \mathrm{N}, 62^{\circ} 28.569^{\prime} \mathrm{W}, 20 \mathrm{~m}, 3 . i v .1995$, Holzenthal, Flint \& Cressa (UMSP000022229) (UMSP, pinned).

Distribution. Venezuela (Sucre).

Etymology. The name is derived from the type locality, the Venezuelan state of Sucre. The name is to be treated as a noun in apposition.

\section{Helicopsyche (Feropsyche) disjuncta, new species}

Fig. 8-14, 87

When viewed laterally, the slender gonocoxite of $H$. disjuncta, new species, strongly resembles that of H. minima Siebold, from which it can be separated by the presence of 

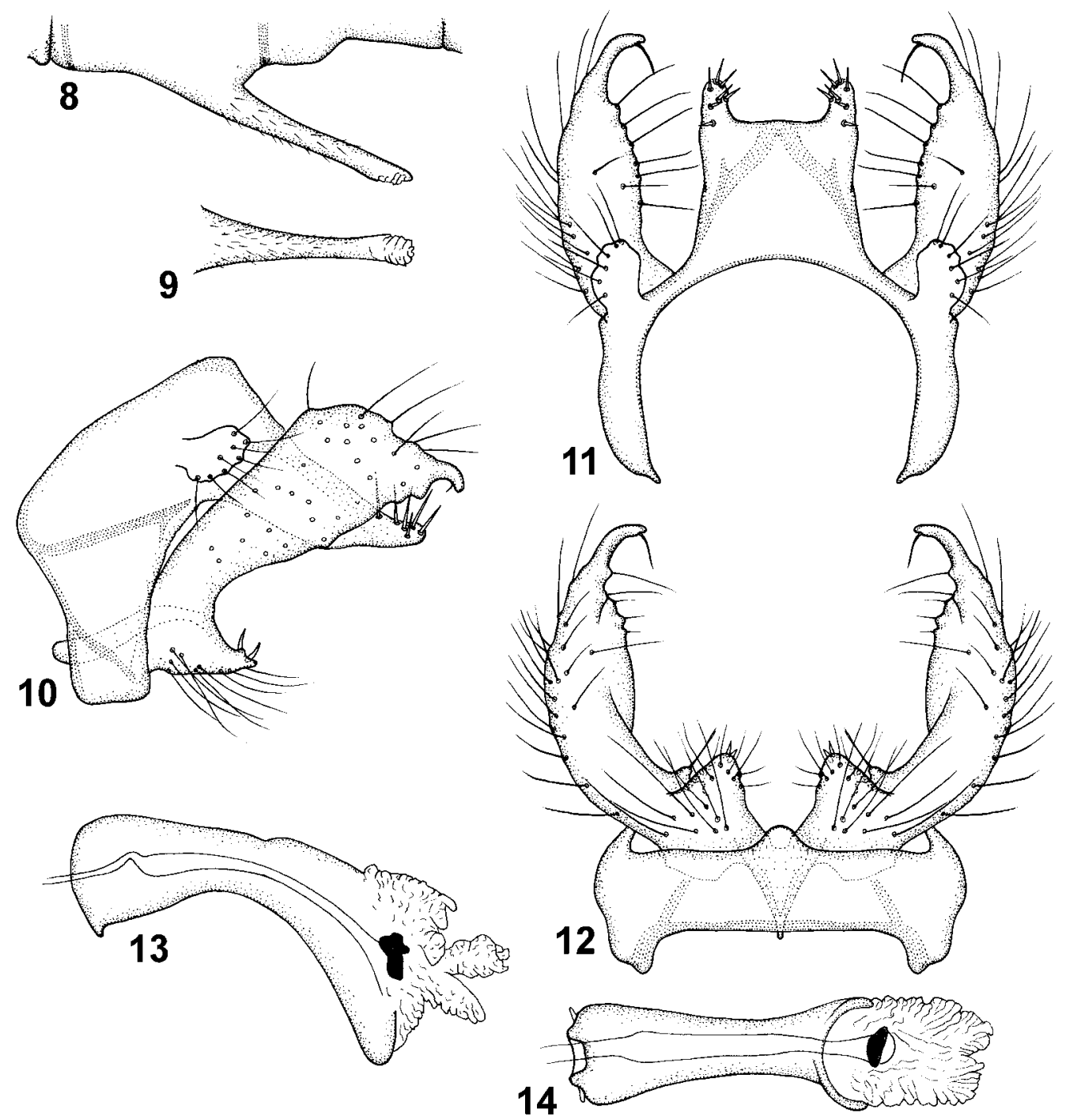

FIGURES 8-14. Helicopsyche disjuncta, new species, holotype. 8-sternum VI process, lateral; 9-sternum VI process, ventral; 10 -male genitalia, lateral; 11—male genitalia, dorsal view; 12male genitalia, ventral; 13-phallus, lateral; 14-phallus, ventral.

Male. Head: Antennal scape about 3/4 as long as eye diameter. Maxillary palp segment equally long, each about $2 / 3$ eye diameter. Cephalic warts longitudinally oval, length about $2 / 3$ eye diameter. Forewing $3.1 \mathrm{~mm}$. Sternum VI process (Fig. 8, 9) nearly $1 / 2$ its segment length, covered by microtrichiae; nearly straight in lateral view (Fig. 8), oriented 
posteroventrally, tubular along its length, except slightly wider at apex; apex lamellate (Fig. 9).

Male genitalia (Fig. 10-14). Segment IX, in lateral view (Fig. 10), with anterior lobe hyperboloid, oriented anteriad, present midlaterally; anterodorsal margin slightly convex; anteroventral margin concave; in dorsal view (Fig. 11), with inner margin widely Ushaped; in ventral view (Fig. 12), with posterior process midventrally; lateral apodeme present as anteroventrally oriented, nearly straight line (Fig. 10), fusing with anterior margin; sub-marginal line absent; tergal transverse apodeme apparently absent; sternal transverse apodeme absent; sternal longitudinal apodeme oriented anterodorsally. Segment X, in lateral view (Fig. 10), oriented posteroventrad, curving posteriorly along its length; dorsally concave; apex narrowly rounded; in dorsal view, (Fig. 11), parallel along its length, apicolateral corners produced posteriorly, leaving a wide, rectangular notch; with about 7 pairs of about equally long megasetae in group at produced corners. Superior appendage (Fig. 10) strongly club-shaped, oriented posteriorly. Primary branch of gonocoxite, in lateral view (Fig. 10), generally widening distally, with weakly undulate dorsal margin; apex strongly produced posteriorly and curving medially; central part of primary branch slightly wider than height of central part of Tergum X (Fig. 10); anterodorsal margin nearly straight, smooth; posteroventral margin without undulations; basimesal lobe cone-shaped in lateral view (Fig. 10), rounded in ventral view (Fig. 12), with weakly concave median margins; with 2 distinct megasetae on apicodorsal margin; basal plate, in lateral view (Fig. 10), slightly sigmoid, wide along its length; in ventral view (Fig. 12), triangular, apex pointed. Phallus, in lateral view (Fig. 13), with anterior half nearly straight, smoothly bent ventrad at midlength, dorsal margin weakly undulating; ventral margin smoothly angled; anterior 1/4 about 11/2 times as broad as its central part (Fig. 13); in ventral view (Fig. 14), phallobase present as narrow, lateral processes; endotheca weakly produced; sperm channel divided into thick posterior and slender anterior parts; posteroventral part strongly sclerotized.

Holotype male: VENEZUELA: Sucre: Parque Nacional Peninsula de Paria, Uquire, Río La Viuda, $10^{\circ} 42.830^{\prime} \mathrm{N}, 61^{\circ} 57.661^{\prime} \mathrm{W}, 15 \mathrm{~m}, 30 . i i i-1 . i v .1995$, Holzenthal, Flint \& Cressa (NMNH, in alcohol).

Distribution. Venezuela (Sucre).

Etymology. The name disjuncta, from the Latin disjunctus, means separate or distinct, and refers to the widely separated lateral corners of the Tergum $\mathrm{X}$ of the male genitalia. The name is to be treated as a noun in apposition.

\section{Helicopsyche (Feropsyche) succincta, new species}

Fig. 15-21, 89

This new species is very similar to $H$. flinti from which it can be distinguished by the absence of a single strong process on the posteroventral margin of the gonocoxite, and the 

grenadensis, $H$. molesta, and $H$. valligera, by the anteriorly oriented, but slightly pointed anterior lobe of segment IX.

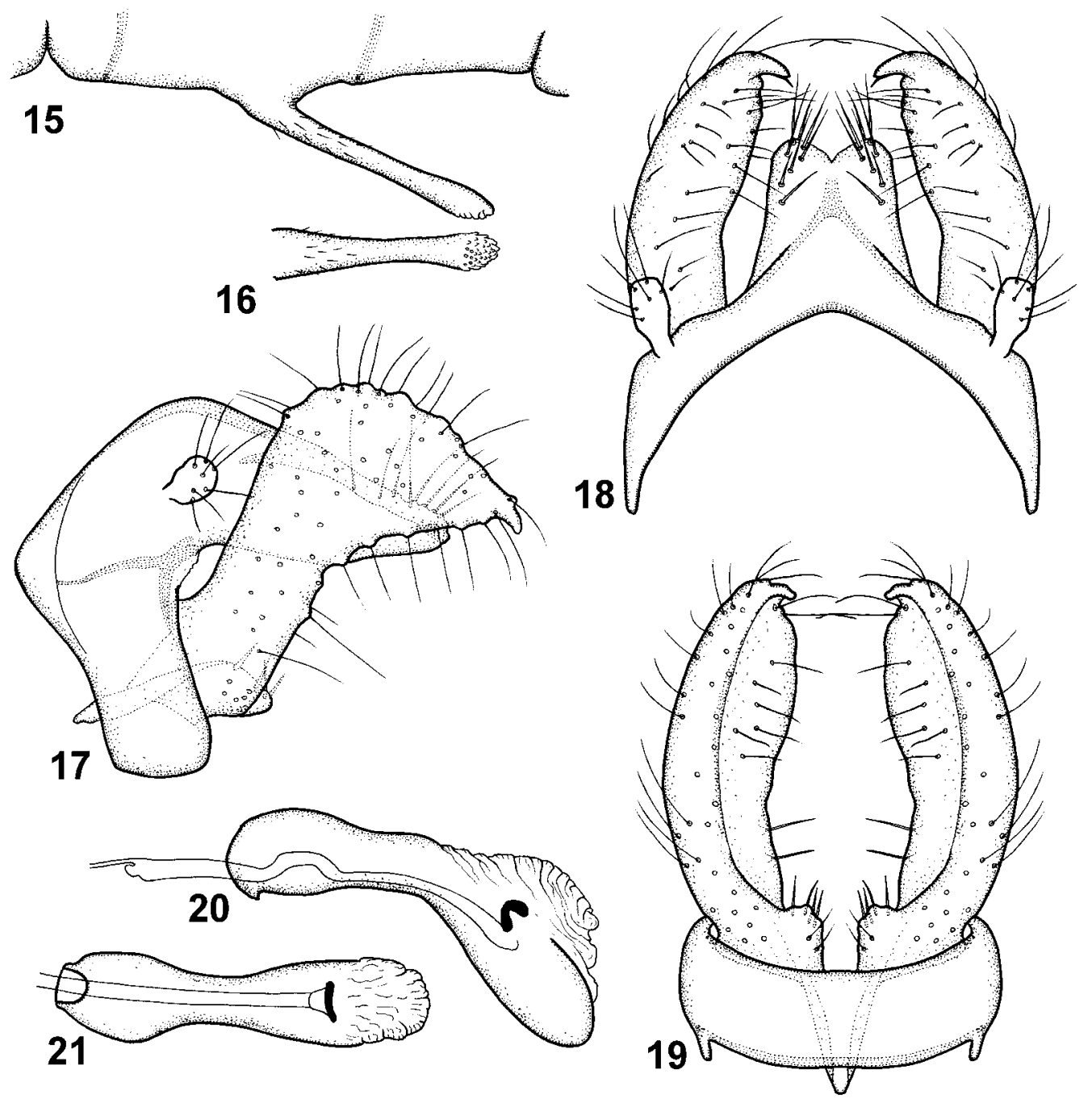

FIGURES 15-21. Helicopsyche succincta, new species, holotype. 15-sternum VI process, lateral; 16-sternum VI process, ventral; 17—male genitalia, lateral; 18—male genitalia, dorsal; 19male genitalia, ventral; 20-phallus, lateral; 21—phallus, ventral.

Male. Head: Antennal scape about as long as eye diameter. Maxillary palp segments equally long, each segment nearly as long as eye diameter. Cephalic warts rounded, convex, about $1 / 2$ as long as eye diameter, with golden brown setae. Forewing golden brown, length 3.9-4.1 mm. Sternum VI process (Fig. 15, 16) nearly $1 / 2$ its segment length, covered by microtrichiae on proximal half; nearly straight in lateral view (Fig. 15), oriented 
posteroventrally; tubular along its length, except wider at apex; apex bearing minute spines (Fig. 16).

Male genitalia (Fig. 17-21). Segment IX, in lateral view (Fig. 17), with anterior lobe hyperboloid, oriented anteriad, present midlaterally; anterodorsal margin nearly straight; anteroventral margin slightly concave; in dorsal view (Fig. 18), with inner margin hyperboloid; in ventral view (Fig. 19), without posterior process; lateral apodeme present as anteriorly oriented undulate line (Fig. 17), fading before reaching anterior margin; submarginal line present; tergal transverse apodeme apparently absent; sternal transverse apodeme absent. Segment X, in lateral view (Fig. 17), oriented posteroventrad, nearly straight along its length; dorsally nearly straight; tapering along its length, apex narrowly rounded; in dorsal view, (Fig. 18), slightly narrowing apically, apex strongly notched; with about 7 pairs of about equally long megasetae in group starting at distal half. Superior appendage (Fig. 17) club-shaped, oriented posteriorly. Primary branch of gonocoxite, in lateral view (Fig. 17), with proximal half about equally broad, strongly widening at distal half, with undulate dorsal margin; apex produced and curving medially; central part of primary branch slightly narrower than height of central part of tergum X (Fig. 17); anterodorsal margin nearly straight, smooth; posteroventral margin weakly undulate; basimesal lobe small, apically rounded in lateral view (Fig. 17), rounded in ventral view (Fig. 19), with nearly straight, parallel median margins; with 4 weak megasetae on dorsal margin; basal plate, in lateral view (Fig. 17), nearly straight, narrow anteriorly; in ventral view (Fig. 19), sharply triangular, apex narrowly rounded. Phallus, in lateral view (Fig. 20), with anterior half nearly straight, smoothly bent ventrad at midlength, dorsal margin undulating; ventral margin angled; anterior 1/4 about 1.5X broader than its central part (Fig. 20); in ventral view (Fig. 21), phallobase absent; endotheca weakly produced; sperm channel divided into long, thick posterior and slender anterior parts; posteroventral part strongly sclerotized.

Holotype male: VENEZUELA: T.F.A. [Territorio Federal Amazonas = Estado Amazonas]: Camp XII, 1950 m, near Pico Phelps, 26.ii.1985, W.E. Steiner, W. Buck, B. Boom, C. Brewer (NMNH, pinned).

Paratype: same data as holotype, except Camp X, $1690 \mathrm{~m}, 0^{\circ} 54^{\prime} \mathrm{N}, 60^{\circ} 2^{\prime} \mathrm{W}$ [sic! is possibly $0^{\circ} 54^{\prime} \mathrm{N}, 66^{\circ} 02^{\prime} \mathrm{W}$ ], 13.ii.1985, W.E. Steiner -1 male (NMNH, pinned).

Distribution. Venezuela (Amazonas).

Etymology. The name succincta, from the Latin succinctus, means short, and refers to the short basimesal process of the gonocoxite. The name is to be treated as a noun in apposition.

\section{Helicopsyche (Feropsyche) camuriensis, new species}

Fig. 22-28, 87

Helicopsyche caligata Flint has a club-shaped gonocoxite similar to that of $H$. camuriensis, but the new species is unique in having a larger anterior lobe on segment IX, the pres- 

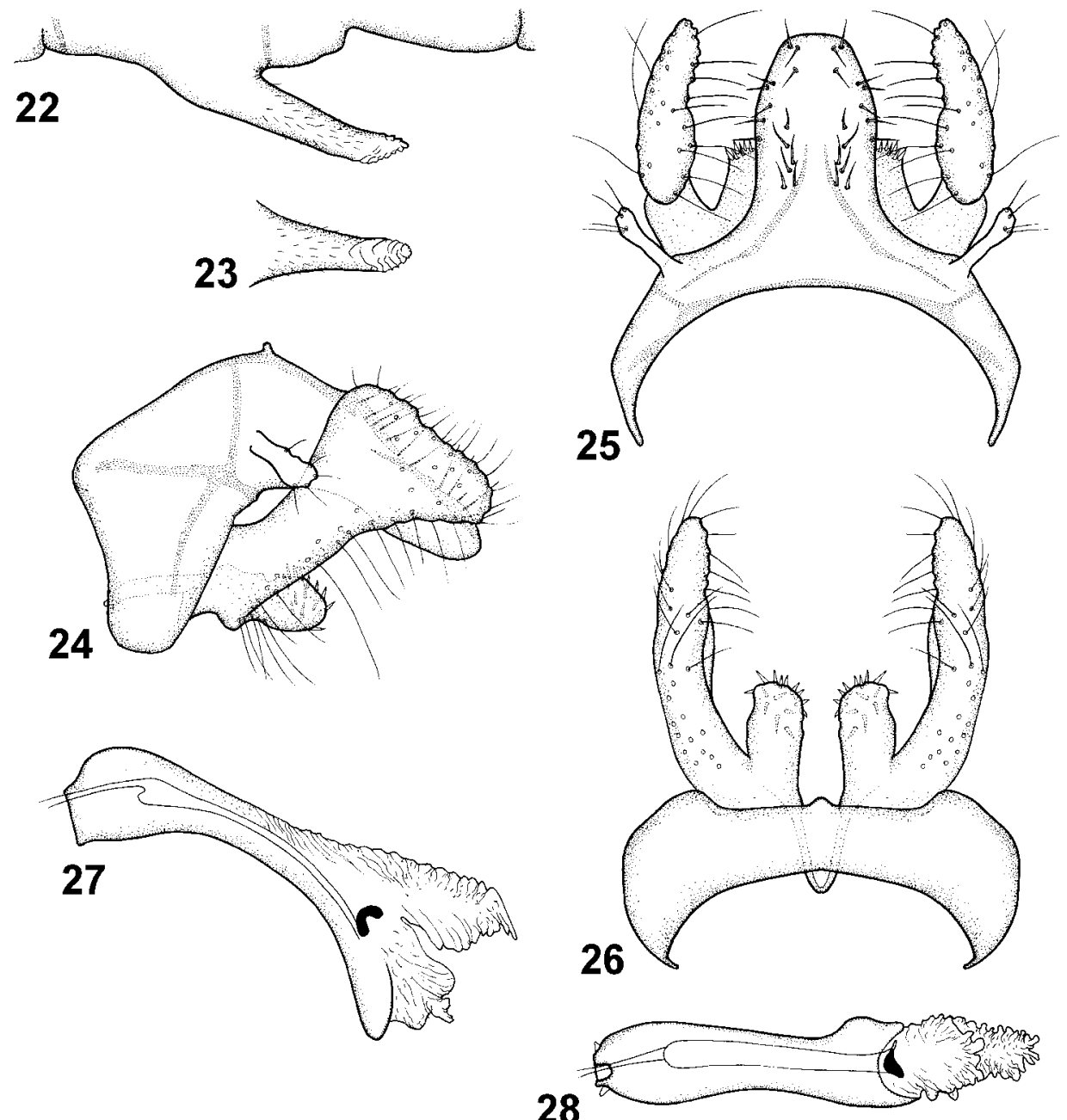

FIGURES 22-28. Helicopsyche camuriensis, new species, holotype. 22-sternum VI process, lateral; 22-sternum VI process, ventral; 24-male genitalia, lateral; 25-male genitalia, dorsal; 26-male genitalia, ventral; 27—phallus, lateral; 28—phallus, ventral.

Male. Head: Antennal scape about $2 / 3$ as long as eye diameter. Maxillary palp segments equally long, each segment as long as eye diameter. Cephalic warts round, small, strongly convex, about $1 / 3$ as long as eye diameter, with pale grey and golden brown setae. Forewing pale golden brown, length 3.8-4.1 mm. Sternum VI process (Fig. 22, 23) about $1 / 3$ its segment length, covered by microtrichiae; nearly straight and slightly tapering in lateral view (Fig. 22), oriented posteroventrally; narrowing along its length in ventral view (Fig. 23); apex bearing ventral lamellae (Fig. 23). 
Male genitalia (Fig. 24-28). Segment IX, in lateral view (Fig. 24), with anterior lobe hyperboloid, oriented anteriad, present midlaterally; anterodorsal margin nearly straight; anteroventral margin shallowly concave; in dorsal view (Fig. 25), with inner margin widely hyperboloid; in ventral view (Fig. 26), with minute posterior process; lateral apodeme present as anteriorly oriented, nearly straight line (Fig. 24), fading before reaching anterior margin; sub-marginal line absent; tergal transverse apodeme present; sternal transverse apodeme present. Segment X, in lateral view (Fig. 24), oriented posteroventrad, nearly straight along its length; dorsally undulate; slightly tapering along its length, apex widely rounded; in dorsal view (Fig. 25), slightly narrowing apically, apex without notch; with about 14 pairs of about equally long megasetae in group starting at proximal half. Superior appendage (Fig. 24) tubular, apex slightly club-shaped, oriented posterolaterally. Primary branch of gonocoxite, in lateral view (Fig. 24), with proximal half about equally broad, strongly widening to club-shaped distal half, with undulate dorsal margin; apex weakly produced, oriented posteriorly; central part of primary branch slightly narrower than height of central part of Tergum X (Fig. 24); anterodorsal margin nearly straight, smooth; posteroventral margin nearly straight at proximal half; basimesal lobe large, protruding primary branch, apically widely rounded in lateral view (Fig. 24), tubular in ventral view (Fig. 26), with nearly straight, sub-parallel median margins; with about 15 short megasetae on dorsal margin; basal plate, in lateral view (Fig. 24), narrow, slightly curving ventrally toward anterior apex; in ventral view (Fig. 26) triangular, apex rounded. Phallus, in lateral view (Fig. 27), with anterior half nearly straight, gently curving ventrad at midlength, dorsal margin nearly straight; ventral margin curving; anterior $1 / 5$ about $2 \mathrm{x}$ broader than its central part (Fig. 27); in ventral view (Fig. 28); phallobase forms minute lateral triangles; endotheca produced into long dorsal lobe; sperm channel divided into thick posterior and slender anterior parts; sclerotized posteroventral part narrow.

Holotype male: VENEZUELA: Dist. Fed. [Districto Federal]: Río Camuri Grande, $1 \mathrm{~km} \mathrm{~S}$ Camuri, (nucleo U.S.B.), $10.616^{\circ} \mathrm{N}, 66.715^{\circ} \mathrm{W}, 30 \mathrm{~m}, 24.1 .1994$, Holzenthal, Cressa \& Rincón (UMSP000022236) (UMSP, pinned).

Paratypes: same data as holotype -3 males, 2 females (UMSP, pinned), 1 male, 1 female (NRM, pinned), 1 male, 1 female (NMNH, pinned), 1 male (IZAM, pinned).

Distribution. Venezuela (Districto Federal).

Etymology. The name camuriensis is derived from the type locality, Río Camuri Grande. The name is to be treated as a noun in the genitive case.

\section{Helicopsyche (Feropsyche) auroa, new species}

Fig. 29-35, 89

The new species is separated from all other American Helicopsyche species by the presence of a short sternum VI process together with a widely triangular gonocoxite with its prominent, sharply tapering basimesal lobe. 
Male. Head: Antennal scape as long as eye diameter and distal maxillay palp segment. Maxillary palp with proximal segment about $2 / 3$ length of distal segment. Cephalic warts rounded, slightly convex, about $1 / 2$ as long as eye diameter, with pale yellow and brown setae. Forewing golden brown, length 4.5-4.6 mm. Sternum VI process (Fig. 29, 30) about $1 / 3$ its segment length, covered by microtrichiae; in lateral view (Fig. 29), nearly straight and slightly tapering before wider apex, oriented posteroventrally; parallel-sided in ventral view (Fig. 30); apex bearing ventral lamellae (Fig. 30).
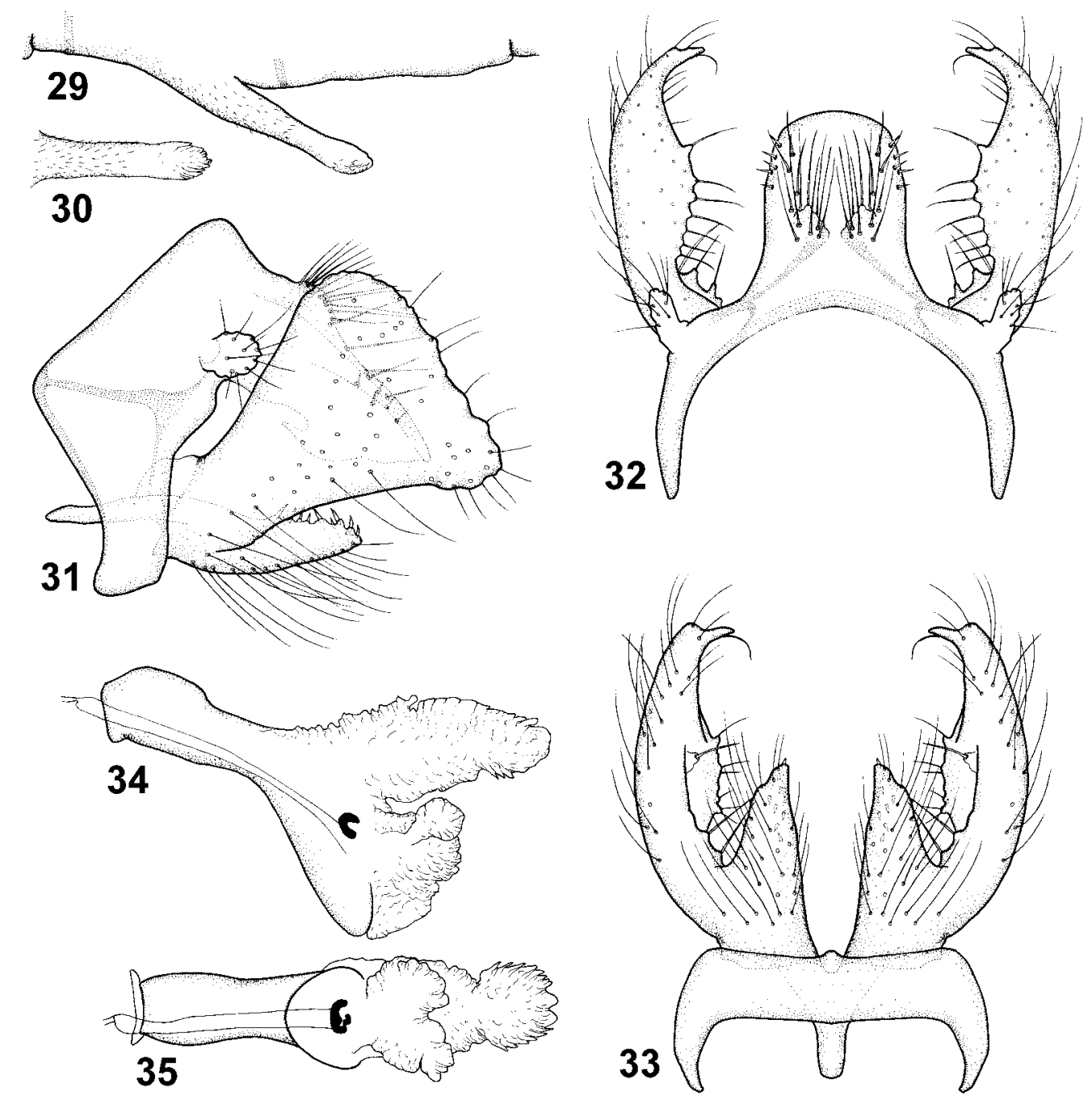

FIGURES 29-35. Helicopsyche auroa, new species, holotype. 29—-sternum VI process, lateral; 30-sternum VI process, ventral; 31-male genitalia, lateral; 32-male genitalia, dorsal; 33-male genitalia, ventral; 34-phallus, lateral; 35-phallus, ventral.

Male genitalia (Fig. 31-35). Segment IX, in lateral view (Fig. 31), with anterior lobe hyperboloid, oriented anteriad, present midlaterally; anterodorsal margin straight; 
anteroventral margin concave ventrally; in dorsal view (Fig. 32), with inner margin widely hyperboloid; in ventral view (Fig. 33), with minute posterior process; lateral apodeme present as anteriorly oriented, nearly straight line (Fig. 31) reaching anterior margin; submarginal line absent; tergal transverse apodeme absent; sternal transverse apodeme absent. Segment X, in lateral view (Fig. 31), oriented posteroventrad, nearly straight but with dorsal lobe at proximal part; slightly tapering along its length, apex slightly pointed; in dorsal view, (Fig. 32), slightly narrowing toward wide, rounded apex, lacking notch; with about 12 pairs of about equally long megasetae in longitudinal group starting at dorsal lobe, and about 5 pairs of smaller megasetae at lateral margin. Superior appendage (Fig. 31) tubular in dorsal view, slightly club-shaped in lateral view, oriented posterolaterally. Primary branch of gonocoxite, in lateral view (Fig. 31), generally widely triangular, with slightly undulate dorsal margin; apex rounded in lateral view, produced into finger-like process visible in dorsal view (Fig. 32); central part of primary branch slightly wider than height of central part of tergum X (Fig. 31); anterodorsal margin nearly straight, smooth; posteroventral margin weakly concave; basimesal lobe large, cone-shaped, strongly protruding primary branch, apically narrowing in lateral and ventral views (Fig. 31, 33), with slightly undulating, diverging, median margins; with about 9 short megasetae on dorsal margin; basal plate, in lateral view (Fig. 31), narrow, slightly sigmoid; in ventral view (Fig. 33), narrowly triangular, apex truncate. Phallus, in lateral view (Fig. 34), anterior half nearly straight, gently bent ventrad at midlength, dorsal margin concave; ventral margin angled; anterior 1/5 about 1.5x broader than its central part (Fig. 34); in ventral view (Fig. 35), phallobase forms narrow, ventral band; endotheca produced into long dorsal lobe; sperm channel divided into long, thick posterior and slender anterior parts; sclerotized posteroventral part narrow.

Holotype male: VENEZUELA: Lara: P.N. [Parque Nacional] Terepaima, Río Auro near Sabana Alta, 944.740'N, 69¹6.614'W, 480 m, 16.vi.2001, Holzenthal, Blahnik, Paprocki, \& Cressa, (UMSP000075028) (UMSP pinned).

Paratypes: VENEZUELA: Ar [Aragua]: Est. Exp. [Estación Experimental] Cataurito, ca. $32 \mathrm{~km}$ E Villa de Cura, $1100 \mathrm{~m}$, O.S. Flint, Jr. — 1 male, 8 females (NMNH, alcohol).

Distribution. Venezuela (Aragua, Lara).

Etymology. auroa, derived from the type locality, Río Auro. The name is to be treated as a noun in apposition.

\section{Helicopsyche (Feropsyche) tachira, new species}

Fig. 36-40, 87

Helicopsyche tachira has a unique hourglass-shaped gonocoxite in lateral view. Tergum X is undivided apically as in $H$. cubana Kingsolver, $H$. guadeloupensis Malicky, $H$. laneblina, new species, H. molesta Botosaneanu, H. ramosi Flint, and H. sigillata Botosa- 
neanu \& Flint, but in $H$. tachira tergum $\mathrm{X}$ is pointed, while it is rounded in the other species.

Male. Head: Antennal scape about 1.5x longer than eye diameter, with pale yellowish setae. Eyes small. Maxillary palp segments equally long, each longer than eye diameter; covered by dark setae. Cephalic warts small, oval, about $0.8 \mathrm{x}$ as long as eye diameter, with dark golden and black setae. Forewing dark golden brown, length $5.9 \mathrm{~mm}$. Sternum VI process absent.

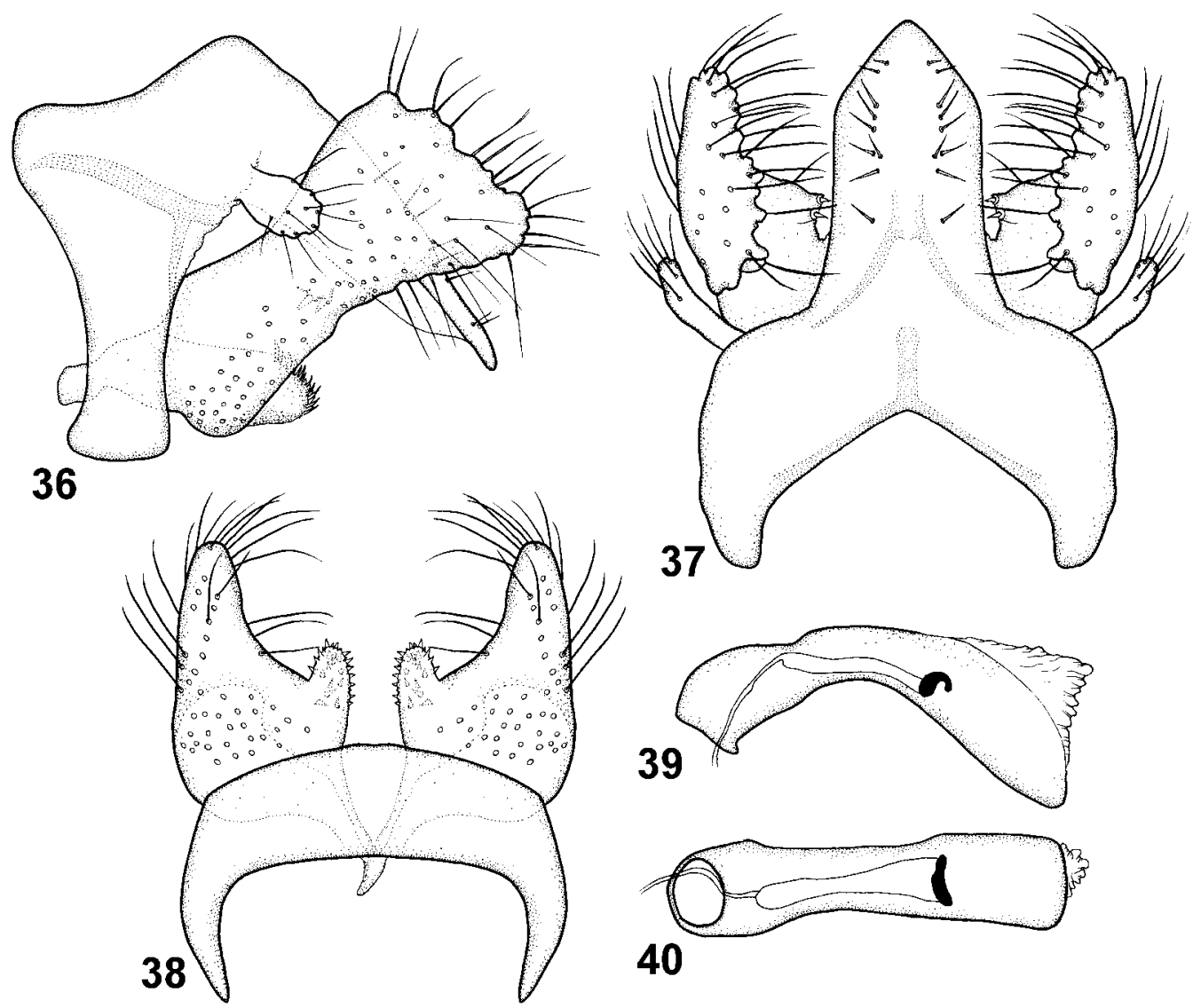

FIGURES 36-40. Helicopsyche tachira, new species, holotype. 36-male genitalia, lateral; 37male genitalia, dorsal; 38—male genitalia, ventral; 39-phallus, lateral; 40—phallus, ventral.

Male genitalia (Fig. 36-40). Segment IX, in lateral view (Fig. 36), with anterior lobe narrowly ellipsoid, oriented anterodorsally, present dorsolaterally; anterodorsal margin concave; anteroventral margin widely concave; in dorsal view (Fig. 37), with inner margin triangular; in ventral view (Fig. 38), without posterior process; lateral apodeme present as anteriorly oriented, slightly sigmoid line (Fig. 36) fading before reaching anterior margin; sub-marginal line absent; tergal transverse apodeme absent; sternal transverse apodeme 
absent. Segment X, in lateral view (Fig. 36), nearly straight, oriented posteroventrad; slightly tapering before narrow apex, apex slightly pointed; in dorsal view (Fig. 37), about parallel-sided proximally to triangular apex, apex without notch; with about 9 pairs of about equally long, weak megasetae in longitudinal group starting at proximal half. Superior appendage (Fig. 36) club-shaped in lateral view, oriented posterolaterally (Fig. 37). Primary branch of gonocoxite, in lateral view (Fig. 36), generally narrowing at midlength, dorsal margin undulate; apex rounded in lateral and dorsal views (Fig. 36, 37); central part of primary branch slightly wider than height of central part of tergum X (Fig. 36); anterodorsal margin concave, smooth; posteroventral margin concave; inside of primary branch strongly widening medially into pointed process bearing 2 megasetae (Fig. 37); basimesal lobe rounded apically, slightly protruding primary branch in lateral view (Fig. 36); with slightly convex, apically diverging median margins (Fig. 38); with nearly 30 short megasetae on dorsal margin; basal plate, in lateral view (Fig. 36), short, thick, slightly bent ventrally, apex truncate; in ventral view (Fig. 38), narrowly pointing anteriorly. Phallus, in lateral view (Fig. 39), with anterior 1/3 nearly straight, strongly bent ventrad at midlength, dorsal margin undulating; ventral margin sharply curved; anterior $1 / 5$ nearly $2 \mathrm{x}$ broader than its central part (Fig. 39); in ventral view (Fig. 40), phallobase absent; endotheca slightly produced; sperm channel divided into short, thick posterior and slender anterior parts; sclerotized posteroventral part wide.

Holotype male: VENEZUELA: Táchira: trib. to Río El Valle, 3.8 km SE El Zumbador, $7^{\circ} 57.411^{\prime} \mathrm{N}, 7^{\circ} 4.394 ' \mathrm{~W}, 2730 \mathrm{~m}, 21 . i v .1995$, Holzenthal, Cressa, Gutic (UMSP000022232) (UMSP, pinned).

Distribution. Venezuela (Táchira).

Etymology. tachira, derived from the type locality, Táchira. The name is to be treated as a noun in apposition.

\section{Helicopsyche (Feropsyche) neblinensis, new species} Fig. 41-47, 88

Together with $H$. lara, new species, $H$. neblinensis has a rounded, triangular gonocoxite, the form being unique for the American Helicopsyche. Helicopsyche neblinensis can be separated from $H$. lara, in dorsal view, by the slightly more slender tergum $\mathrm{X}$ having only five pairs of dorsal setae, and in lateral view, by the slightly wider gonocoxite.

Male. Head: Antennal scape about as long as eye diameter. Maxillary palp segments equally long, each segment slightly shorter than eye diameter. Cephalic warts oval, slightly convex, with golden brown and grey setae. Forewing golden brown-grey, length 3.1-3.5 mm. Sternum VI process (Fig. 41, 42) nearly $2 / 5$ its segment length, covered by microtrichiae; in lateral view (Fig. 41), slightly curving posteriorly and tapering before apex, oriented posteriorly; distally parallel-sided in ventral view (Fig. 42); apex bearing minute ventral lamellae and spines (Fig. 42). 

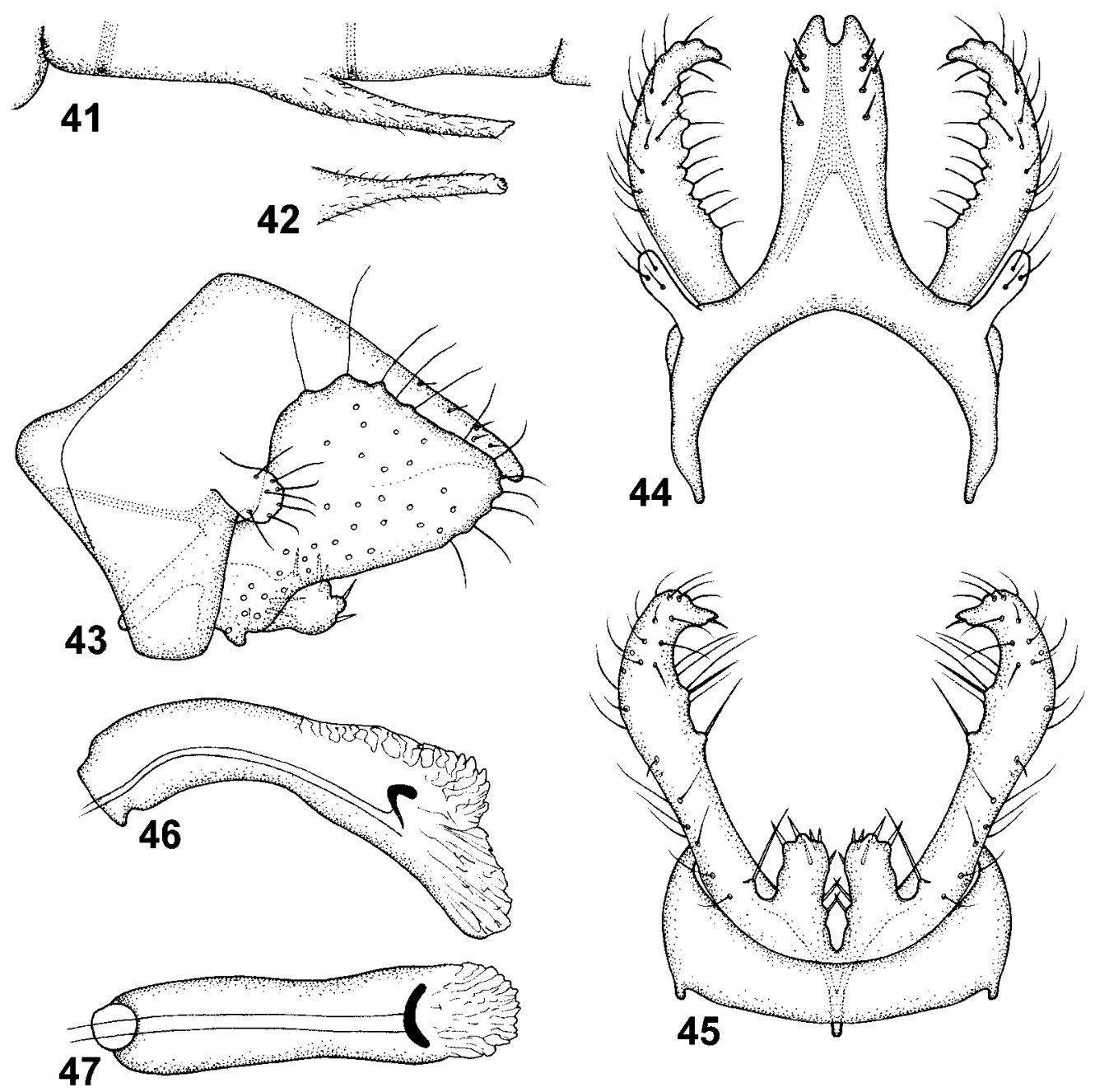

FIGURES 41-47. Helicopsyche neblinensis, new species, holotype. 41-sternum VI process, lateral; 42 — sternum VI process, ventral; 43 —male genitalia, lateral; 44—male genitalia, dorsal; 45male genitalia, ventral; 46-phallus, lateral; 47-phallus, ventral.

Male genitalia (Fig. 43-47). Segment IX, in lateral view (Fig. 43), with anterior lobe hyperboloid, oriented anteriad, present ventrolaterally; anterodorsal and anteroventral margins shallowly concave; in dorsal view (Fig. 44), with inner margin widely ellipsoid; in ventral view, (Fig. 45) without posterior process; lateral apodeme present as anterodorsally oriented, nearly straight line (Fig. 43) nearly reaching anterior margin; sub-marginal line present; tergal transverse apodeme absent; sternal transverse apodeme absent. Segment X, in lateral view (Fig. 43), oriented posteroventrad, nearly straight; strongly tapering along its length, apex slightly pointed and curving ventrally; in dorsal view (Fig. 44), slightly narrowing toward apex; apex deeply and narrowly notched (Fig. 44); with 5 pairs of about 
equally long, weak megasetae in longitudinal group starting at distal half. Superior appendage (Fig. 43) tubular in dorsal view, slightly club-shaped in lateral view, oriented posterolaterally. Primary branch of gonocoxite, in lateral view (Fig. 43), generally widely triangular, with slightly undulate dorsal margin; apex rounded in lateral view, produced into hook-like process visible in dorsal view (Fig. 44); central part of primary branch wider than height of central part of tergum X (Fig. 43); anterodorsal margin convex, smooth; posteroventral margin weakly sigmoid.; basimesal lobe large, tubular, protruding primary branch and with undulating apex (Fig. 43, 45); with slightly converging median margins armed with strong setae; with about 6 long megasetae on dorsal margin; basal plate, in lateral view (Fig. 43), nearly straight, oriented anteroventrally, apex rounded; in ventral view (Fig. 45), strongly narrowing toward apex. Phallus, in lateral view (Fig. 46), with anterior half curving posteriorly, gently bent ventrad at midlength, dorsal margin convex along its length; ventral margin curving; anterior $1 / 5$ about as broad as its central part (Fig. 46); in ventral view (Fig. 47), tubular along its length; phallobase absent; endotheca slightly produced; sperm channel undivided; sclerotized posteroventral part narrow.

Holotype male: VENEZUELA: T.F.A. [Territorio Federal Amazonas = Estado Amazonas]: Cerro de la Neblina, Basecamp, $0^{\circ} 51^{\prime} \mathrm{N}, 66^{\circ} 10^{\prime} \mathrm{W}, 140$ m, 13-15.iii.1984, O.S. Flint, Jr. \& J. Louton (NMNH, pinned).

Paratypes: same data as holotype -8 males, 9 females (NMNH, pinned); same data as holotype, except 20-24.iii.1984, O.S. Flint, Jr. \& J. Louton - 30 males, 50 females (NMNH, alcohol), 2 males, 2 females (UMSP, alcohol), 2 males, 2 females (NRM, alcohol), 2 males, 2 females (IZAM, alcohol); same data as holotype, except $0^{\circ} 50^{\prime} \mathrm{N}$, 669'44"W, 140 m, 13-20.ii.1984, D. Davis \& T. McCabe - 1 male, 6 females (NMNH, alcohol); same data as holotype, except $0^{\circ} 50^{\prime} \mathrm{N}, 66^{\circ} 9^{\prime} 44^{\prime \prime} \mathrm{W}, 140 \mathrm{~m}, 21-29 . i i .1984$, D. Davis \& T.McCabe -3 males, 4 females (NMNH, alcohol); same data as holotype, except $0^{\circ} 50^{\prime} \mathrm{N}, 66^{\circ} 9^{\prime} 44^{\prime \prime} \mathrm{W}, 140 \mathrm{~m}, 1-10$. iii.1984, D. Davis \& T. McCabe - 14 males, 19 females (NMNH, alcohol); same data as holotype, except 8-9.ii.1985, W.E.Steiner - 7 males, 10 females (NMNH, pinned); same data as holotype, except 10-20.ii.1985, P.J. \& P.M. Spangler, R.A. Faitoute, \& W.E. Steiner -4 females (NMNH, pinned); same data as holotype, except Camp IV, 058'N, 6557'W, 760 m, 15-18.iii.1984, O.S. Flint, Jr. — 2 males (NMNH, alcohol).

Distribution. Venezuela (Amazonas).

Etymology. neblinensis, derived from the type locality, Cerro de la Neblina. The name is to be treated as a noun in the genitive case.

\section{Helicopsyche (Feropsyche) venezuelensis, new species}

Fig. 48-54, 88

The gonocoxite of $H$. venezuelensis, new species, is distally rounded and club-shaped as in H. falcigona Botosaneanu \& Flint; it can be distinguished from that species by its nearly 


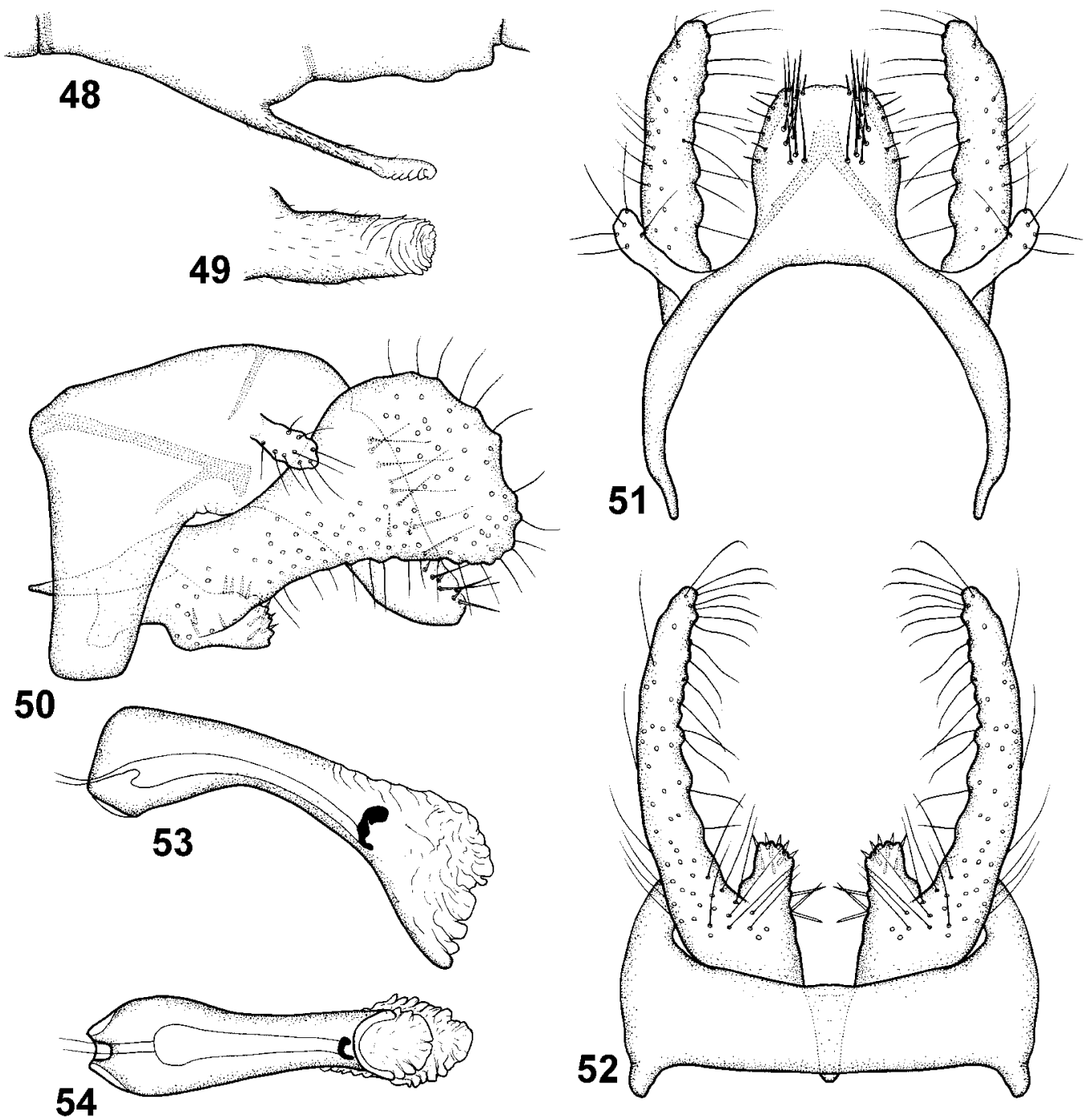

FIGURES 48-54. Helicopsyche venezuelensis, new species, holotype. 48-sternum VI process, lateral; 49-sternum VI process, ventral; 50—male genitalia, lateral; 51-male genitalia, dorsal; 52-male genitalia, ventral; 53-phallus, lateral; 54-phallus, ventral.

Male. Head: Antennal scape about $2 / 3$ as long as eye diameter. Maxillary palp segments equally long, each segment as long as scape. Cephalic warts rounded, convex, about $1 / 3$ as long as eye diameter. Forewing golden brown, length $4.4 \mathrm{~mm}$. Sternum VI process (Fig. 48, 49) 2/5 its segment length, covered by microtrichiae; in lateral view (Fig. 48), slightly curving posteriorly, slender before wide apex; wide, parallel-sided in ventral view (Fig. 49); apex bearing numerous ventral lamellae (Fig. 49). 
Male genitalia (Fig. 50-54). Segment IX, in lateral view (Fig. 50), with anterior lobe slightly developed, oriented anteriad and located dorsolaterally; anterodorsal and anteroventral margins nearly straight; in dorsal view (Fig. 51), with inner margin widely ellipsoid; in ventral view (Fig. 52), without posterior process; lateral apodeme present as anteriorly oriented, nearly straight line (Fig. 50) reaching anterior margin; sub-marginal line absent; tergal transverse apodeme short; sternal transverse apodeme short. Segment X, in lateral view (Fig. 50), oriented posteroventrad, subapically nearly straight, apex slightly curving posteriad; slightly tapering along its length, apex rounded; in dorsal view (Fig. 51), slightly wider at midlength; apex without notch (Fig. 51); with about 11 pairs of about equally long, weak megasetae in longitudinal group starting at proximal half. Superior appendage (Fig. 50), tubular in dorsal view, slightly club-shaped in lateral view; oriented posterolaterally. Primary branch of gonocoxite, in lateral view (Fig. 50), generally widely club-shaped distally, with slightly undulate dorsal margin; apex rounded in lateral and dorsal views (Fig. 50, 51); central part of primary branch narrower than height of central part of tergum X (Fig. 50); anterodorsal margin concave, smooth; posteroventral margin concave, with small undulations; basimesal lobe large, rectangular and protruding primary branch in lateral view (Fig. 50); in ventral view, tubular (Fig. 52), with slightly diverging median margins armed with strong setae; with about 10 long megasetae on dorsal margin; basal plate, in lateral view (Fig. 50), slightly curving dorsally, oriented anteroventrally, apex pointed; in ventral view (Fig. 52), slightly narrowing toward rounded apex. Phallus, in lateral view (Fig. 53), gently bent ventrad at midlength, dorsal margin nearly straight along its length; ventral margin deeply concave; anterior $1 / 5$ about $2 x$ broader than its central part (Fig. 53); in ventral view (Fig. 54) tapering along its length; phallobase apparently present laterally; endotheca slightly produced (Fig. 53); sperm channel divided into wide posterior and narrow anterior parts; sclerotized posteroventral part narrow (Fig. 53).

Holotype male: VENEZUELA: Miranda: Río Caruao, $1.6 \mathrm{~km} \mathrm{~S}$ Caruao, $10.597^{\circ} \mathrm{N}, 66.346^{\circ} \mathrm{W}, 5 \mathrm{~m}, 26 . i .1994$, Holzenthal, Cressa, \& Rincón (UMSP000022215) (UMSP, pinned).

Distribution. Venezuela (Miranda).

Etymology. venezuelensis, derived from the type country, Venezuela. The name is to be treated as a noun in the genitive case.

\section{Helicopsyche (Feropsyche) lara, new species} Fig. 55-61, 86.

Together with $H$. neblinensis, $H$. lara has a rounded, triangular gonocoxite which is unique among American Helicopsyche. Helicopsyche lara can be separated from H. neblinensis, in dorsal view, by a slightly wider tergum $\mathrm{X}$ having about 16 pairs of dorsal setae, and in lateral view, by the slightly more slender gonocoxite. 
Male. Head: Antennal scape as long as eye diameter, with pale yellowish setae. Maxillary palp segments equally long, with dark brown and grey setae. Cephalic warts oval, about half as long as eye diameter; with yellowish setae, some dark brown near lateral margins. Forewing golden brown, length 5.1-5.4 mm. Sternum VI process (Fig. 55, 56) 1/ 3 its segment length, covered by microtrichiae; in lateral view (Fig. 55), nearly straight, slender along its length; in ventral view (Fig. 49), with proximal half slightly tapering, in distal half parallel-sided; apex bearing numerous ventral lamellae (Fig. 56).
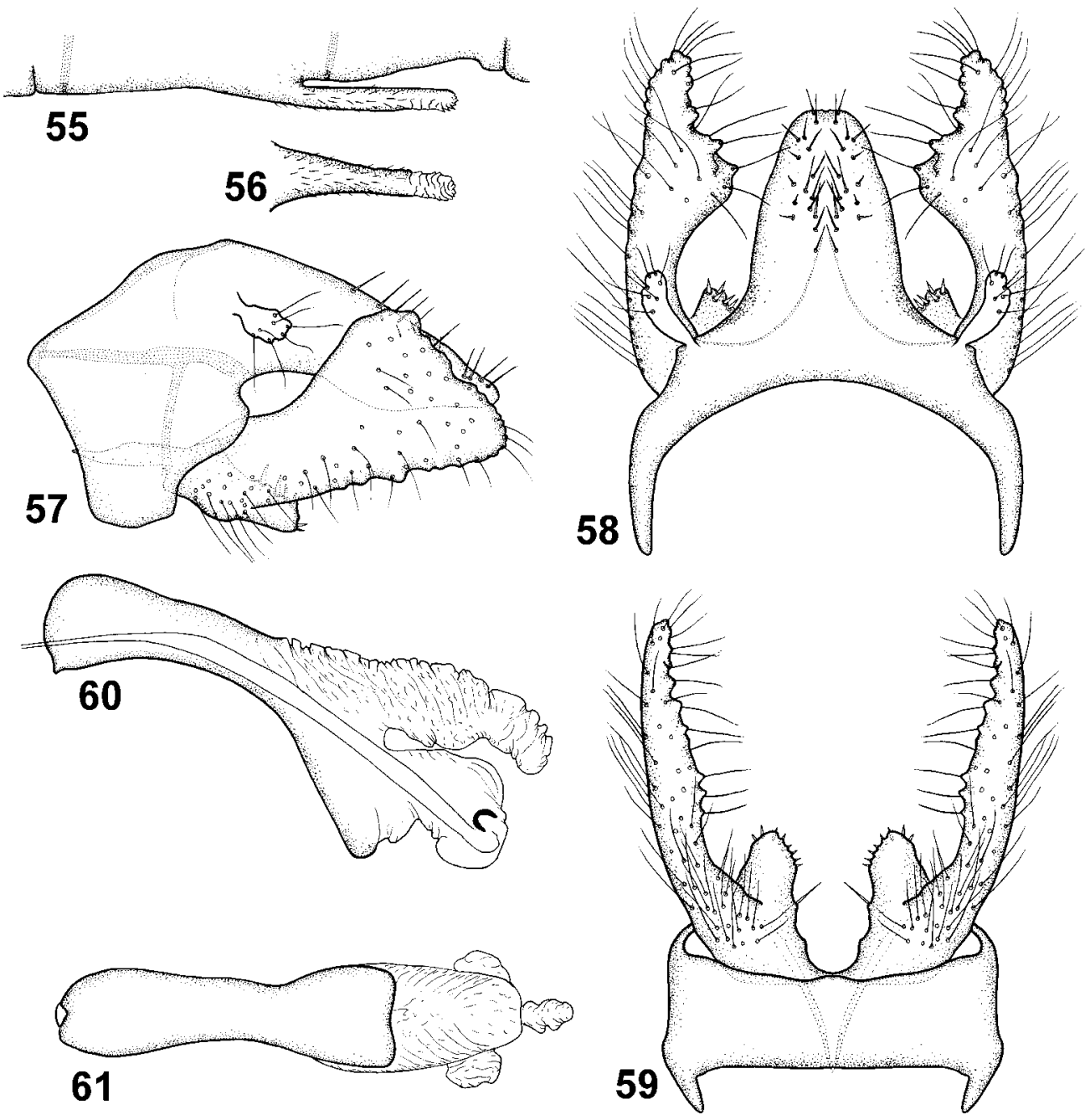

FIGURES 55-61. Helicopsyche lara, new species, holotype. 55-sternum VI process, lateral; 56-sternum VI process, ventral; 57-male genitalia, lateral; 58—male genitalia, dorsal; 59-male genitalia, ventral; 60-phallus, lateral; 61-phallus, ventral.

Male genitalia (Fig. 57-61). Segment IX, in lateral view (Fig. 57), with anterior lobe triangular, oriented anteriad and located at midlaterally on segment; anterodorsal and 
anteroventral margins slightly concave; in dorsal view (Fig. 58), with inner margin widely ellipsoid; in ventral view (Fig. 59), with minute posterior process; lateral apodeme present as anteriorly oriented, nearly straight line (Fig. 57) reaching anterior margin; sub-marginal line absent; tergal transverse apodeme narrow; sternal transverse apodeme well developed. Segment $X$, in lateral view (Fig. 57), oriented posteroventrad, nearly straight; proximal half with dorsal and ventral margins parallel, distal half tapering toward rounded apex; in dorsal view (Fig. 58), slightly narrowing distally; apex without notch (Fig. 58); with about 16 pairs of about equally long megasetae in longitudinal group starting at midway on segment. Superior appendage (Fig. 57) club-shaped in lateral and dorsal views (Fig. 57, 58); curving posteriorly in dorsal view (Fig. 58). Primary branch of gonocoxite, in lateral view (Fig. 57), generally triangular, with undulate dorsal margin; apex rounded in lateral and dorsal views (Fig. 57, 58); central part of primary branch about as wide as height of central part of tergum X (Fig. 57); anterodorsal margin nearly straight, smooth; posteroventral margin nearly straight, undulated; basimesal lobe large, rectangular and protruding primary branch in lateral view (Fig. 57); in ventral view, cone-shaped (Fig. 59); with slightly undulating and diverging median margins armed with a strong seta; with about 8 short megasetae on apical margin; basal plate, in lateral view (Fig. 57), nearly straight, apex pointed; in ventral view (Fig. 59), strongly pointing anteriorly. Phallus, in lateral view (Fig. 60), gently bent ventrad at midlenth, dorsal margin nearly straight along its length; ventral margin gently concave; anterior $1 / 5$ nearly $1.5 x$ broader than its central part (Fig. 60); in ventral view (Fig. 61), tapering toward midlength; phallobase apparently absent; endotheca strongly produced (Fig. 60); sperm channel undivided; sclerotized posteroventral part narrow (Fig. 60), forming a truncate plate in ventral view (Fig. 61).

Holotype male: VENEZUELA: Lara: Parque Nacional Dinira, Quebrada Buenos Aires, $9^{\circ} 36.407^{\prime} \mathrm{N}, 7^{\circ} 04.178^{\prime} \mathrm{W}, 1850$ m, 18-19.vi.2001, Holzenthal, Blahnik, Paprocki, \& Cressa, (UMSP000074735) (UMSP, pinned).

Paratypes: same data as holotype - 19 males, 19 females (UMSP, pinned); same data as holotype, except Quebrada Las Minas, $9^{\circ} 36.263^{\prime} \mathrm{N}, 70^{\circ} 04.167^{\prime} \mathrm{W}, 1825 \mathrm{~m}$, 20.vi.2001, Holzenthal, Blahnik, Paprocki, \& Cressa - 1 male, 1 female (IZAM, pinned), 1 male (UMSP, pinned), 1 male (NRM, pinned).

Distribution. Venezuela (Lara).

Etymology. lara, derived from the type locality, Lara. The name is to be treated as a noun in apposition.

\section{Helicopsyche (Feropsyche) laneblina, new species}

Fig. 62-66, 90

The species is unique in America in having the gonocoxite wide, straight, apically rounded, and parallel-sided along its length. Other species, such as $H$. guadeloupensis Malicky, H. hageni Banks, H. linabena, new species, and H. rentzi Denning \& Blickle also 
have wide, nearly parallel-sided gonocoxites, but these are bent posteriad. Tergum $\mathrm{X}$ is undivided apically as in $H$. cubana, $H$. guadeloupensis, H. molesta, $H$. ramosi, H. sigillata, and $H$. tachira, but can be distinguished from these species by the hidden basimesal lobe of its gonocoxite when viewed laterally.

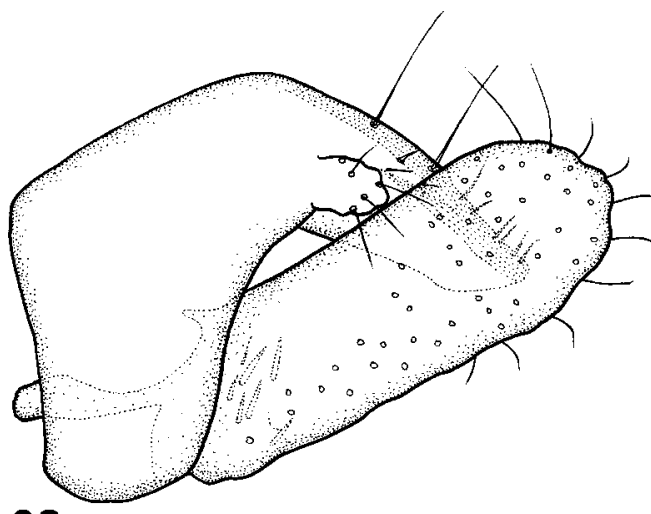

62
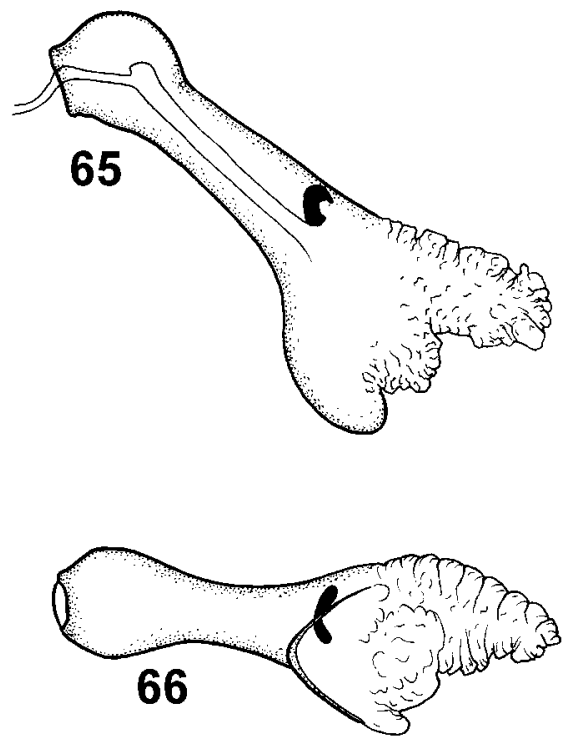

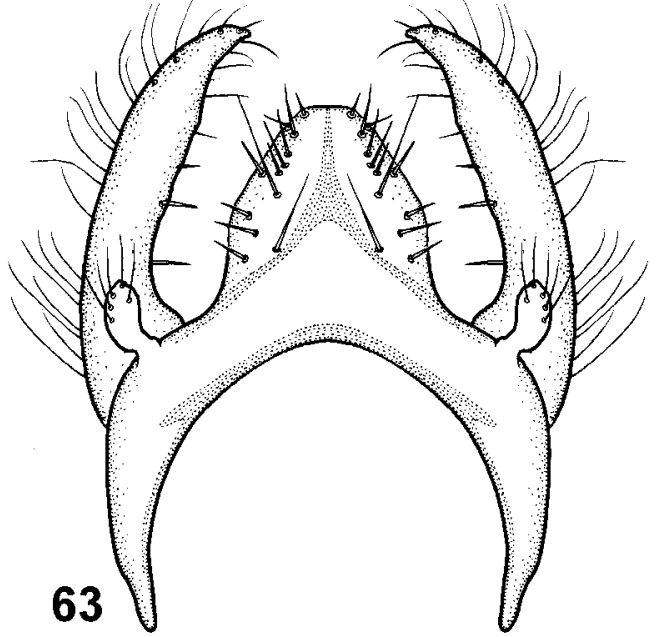

63

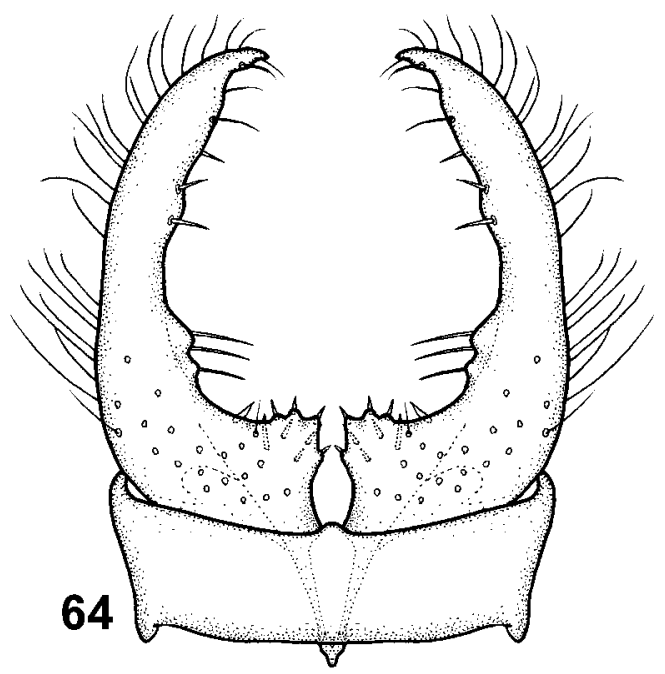

FIGURES 62-66. Helicopsyche laneblina, new species, holotype. 62-male genitalia, lateral; 63-male genitalia, dorsal; 64-male genitalia, ventral; 65-phallus, lateral; 66-phallus, ventral.

Male. Head: Antennal scape slightly shorter than eye diameter. Maxillary palp segments equally long, each segment as long as eye diameter. Cephalic warts rounded, strongly convex, about $2 / 3$ as long as eye diameter, with dark golden-brown setae. Forewing golden-brown, length $4.0 \mathrm{~mm}$. Sternum VI process absent. 
Male genitalia (Fig. 62-66). Segment IX, in lateral view (Fig. 62), with anterior lobe triangular, oriented anterodorsad and located midlaterally on segment; anterodorsal margin nearly straight, anteroventral margin shallowly concave; in dorsal view (Fig. 63), with inner margin widely ellipsoid; in ventral view (Fig. 64), with small posterior process; apodemes apparently absent. Segment X, in lateral view (Fig. 62), oriented posteroventrad, nearly straight; proximal half with dorsal and ventral margins parallel, distal half slightly tapering toward narrowly rounded apex; in dorsal view (Fig. 63), proximally parallelsided, distally narrowing toward apex; apex without notch (Fig. 63); with about 10 pairs of about equally long megasetae in longitudinal group starting at midlength of segment; and 2 pairs of very long megasetae in longitudinal line starting at proximal half (Fig. 62). Superior appendage (Fig. 62) club-shaped in dorsal view, tubular in lateral view (Fig. 62, 63); curving posteriorly in dorsal view (Fig. 62). Primary branch of gonocoxite, in lateral view (Fig. 62), generally nearly straight and with parallel dorsal and ventral margins along its length; apex rounded in lateral view, slightly hooked in dorsal view (Fig. 62, 63); central part of primary branch about $1.3 \mathrm{x}$ as wide as height of central part of tergum $\mathrm{X}$ (Fig. 62); anterodorsal margin nearly straight, smooth; posteroventral margin nearly straight, slightly undulated; basimesal lobe minute, not visible in lateral view, triangular in ventral view (Fig. 64), and armed with about 9 dorsal megasetae (Fig. 64); with slightly undulating median margins; basal plate, in lateral view (Fig. 62), nearly straight, apex clubshaped; in ventral view, (Fig. 64) strongly pointing anteriorly. Phallus, in lateral view (Fig. 65), nearly straight along its length; ventral margin gently concave; anterior 1/5 nearly $1.5 \mathrm{x}$ broader than its central part (Fig. 65); in ventral view (Fig. 66), tapering toward midlength; phallobase apparently absent; endotheca strongly produced into dorsodistal lobe (Fig. 65); sperm channel divided into thick posterior and slender anterior parts; sclerotized posteroventral part wide (Fig. 65).

Holotype male: VENEZUELA: T.F.A. [Territorio Federal Amazonas = Estado Amazonas]: Camp VII, Cerro de la Neblina, $0^{\circ} 51^{\prime} \mathrm{N}, 65^{\circ} 58^{\prime} \mathrm{W}, 1800 \mathrm{~m}, 30 . \mathrm{i}-10 . i i .1985$, P.J. \& P.M. Spangler, \& R.A. Faitoute (NMNH, pinned).

Distribution. Venezuela (Amazonas).

Etymology. laneblina, derived from the type locality, Cerro de la Neblina. The name is to be treated as a noun in apposition.

\section{Helicopsyche (Feropsyche) linabena, new species} Fig. 67-71, 87

In lateral view, the shape of the gonocoxite and tergum $\mathrm{X}$ makes this species very similar to $H$. hageni. The two species can be discriminated by the absence of a distinct basimesal lobe and thicker phallus in $H$. linabena, new species.

Male. Head: Antennal scape about as long as eye diameter. Maxillary palp segments equally long, each segment as long as eye diameter. Cephalic warts not visible. Forewing 

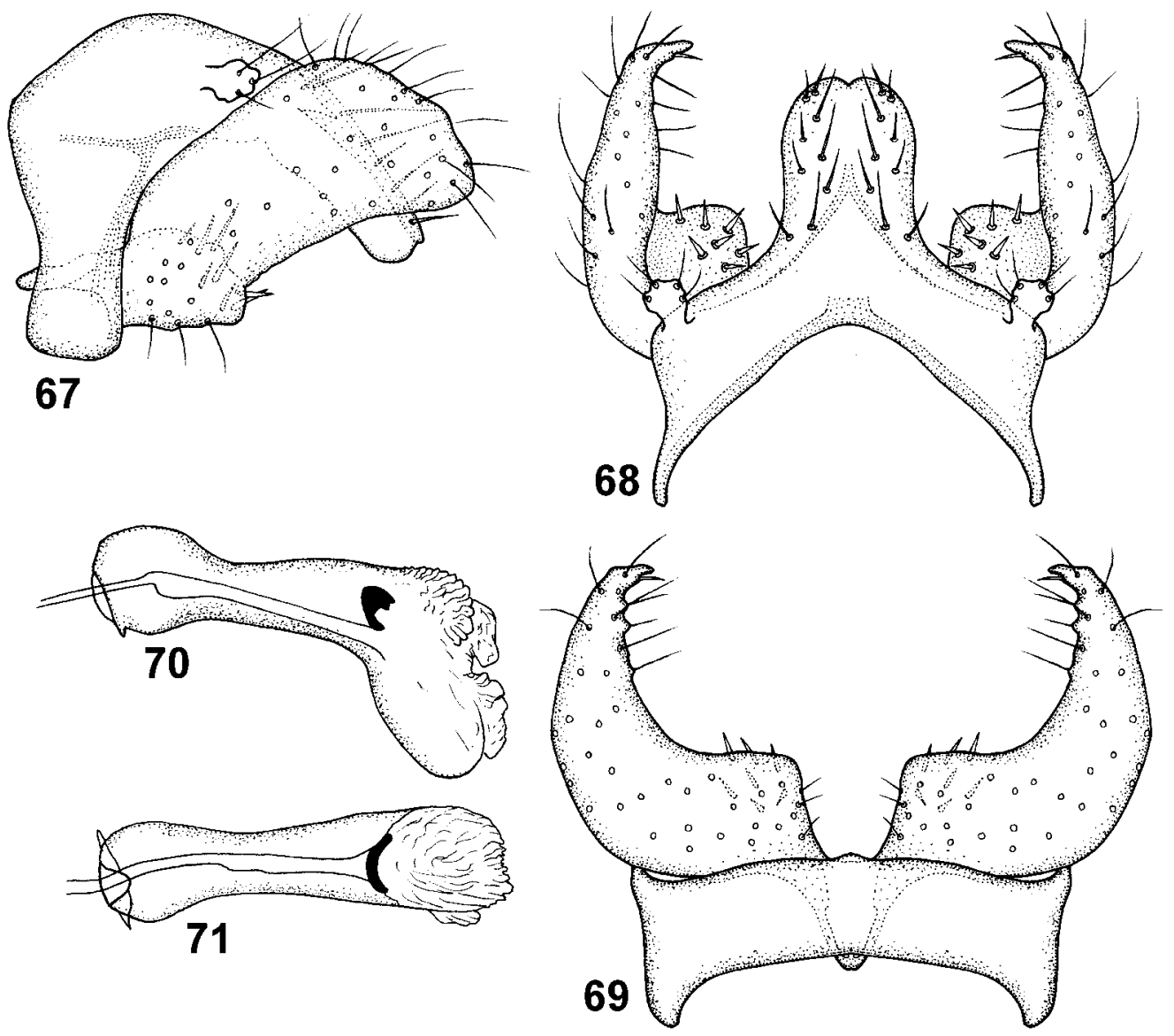

FIGURES 67-71. Helicopsyche linabena, new species, holotype. 67-male genitalia, lateral; 68-male genitalia, dorsal; 69-male genitalia, ventral; 70—phallus, lateral; 71—phallus, ventral.

Male genitalia (Fig. 67-71). Segment IX, in lateral view (Fig. 67), with anterior lobe widely triangular, oriented anteriad, located dorsolaterally on segment; anterodorsal margin nearly straight, anteroventral margin shallowly concave; in dorsal view (Fig. 68), with inner margin hyperboloid; in ventral view (Fig. 69), with minute posterior process; lateral apodeme short, extending slightly anteriorly of midlateral, transverse sternal process present, transverse tergal apodeme absent. Segment X, in lateral view (Fig. 67), curving posteroventrad; slightly tapering along its length toward rounded apex; in dorsal view (Fig. 68), proximally parallel-sided, distally rounded toward apex; apex with V-shaped notch (Fig.68); with about 9 pairs of about equally long megasetae in longitudinal group starting at proximal half on segment (Fig. 67). Superior appendage (Fig. 67) irregularly 
club-shaped in lateral and dorsal views (Fig. 67, 68); nearly straight. Primary branch of gonocoxite, in lateral view (Fig. 67), generally curving posteriorly, slightly widening distally along its length; apex rounded in lateral view, hooked in dorsal view (Fig. 67, 68); central part of primary branch about $2 \mathrm{x}$ as wide as height of central part of tergum X (Fig. 67); anterodorsal margin nearly straight, smooth; posteroventral margin shallowly concave, smooth; basimesal lobe minute, slightly proceeding primary branch in lateral view, forming rounded plate in ventral view (Fig. 69) and armed with about 8 dorsal megasetae (Fig. 67, 69); with smooth, slightly diverging median margins; basal plate, in lateral view (Fig. 67), nearly straight, apex narrowly rounded; in ventral view (Fig. 69), triangular, apically rounded. Phallus, in lateral view (Fig. 70), proximally nearly straight; ventral margin strongly bent ventrad at distal $1 / 3$; anterior $1 / 5$ more than $1.5 \mathrm{x}$ broader than its central part (Fig. 70); in ventral view (Fig. 71), tapering toward proximal 1/3; phallobase forms small lateral triangular (Fig. 71); endotheca slightly produced into dorsodistal lobe (Fig. 70); sperm channel divided into thick posterior and slender anterior parts; sclerotized posteroventral part wide (Fig. 70).

Holotype male: VENEZUELA: T.F.A. [Territorio Federal Amazonas = Estado Amazonas]: Camp IV, Cerro de la Neblina, $0^{\circ} 58^{\prime} \mathrm{N}, 65^{\circ} 57^{\prime} \mathrm{W}, 760 \mathrm{~m}, 15-18 . i i i .1984$, O.S. Flint, Jr. (NMNH, pinned).

Paratypes: same data as holotype -1 male, 5 females (NMNH).

Distribution. Venezuela (Amazonas).

Etymology. The name linabena is an anagram of the name of the type locality, Cerro de la Neblina. The name is to be treated as a noun in apposition.

\section{Helicopsyche (Feropsyche) circulata, new species}

Fig. $72-78,90$

The three species, $H$. circulata, new species, $H$. perija, new species, and $H$. planorboides Machado, all have a characteristically wide and rounded distal part of the gonocoxite. In $H$. circulata, the anterodorsal margin of the gonocoxite is nearly straight, while in $H$. planorboides it is strongly concave. Also, tergum $\mathrm{X}$ is simple in $H$. circulata, while in $H$. planorboides a pair of lateral lobes originate midway on the segment. Helicopsyche circulata can be separated from $H$. perija by the shorter anterior lobe of segment IX, and the longer sternum VI process.

Male. Head: Antennal scape as long as eye diameter. Maxillary palp segments equally long, each segment as long as eye diameter. Cephalic warts oval, strongly convex, about half as long as eye diameter; with pale grey and golden brown setae. Forewing golden brown, length $4.1-4.3 \mathrm{~mm}$. Sternum VI process (Fig. 72, 73) nearly $2 / 3$ its segment length, covered by microtrichiae; in lateral view (Fig. 72), nearly straight, slightly tapering along its length; in ventral view (Fig. 73), slightly tapering; apex bearing numerous ventral thorny lamellae (Fig. 73). 


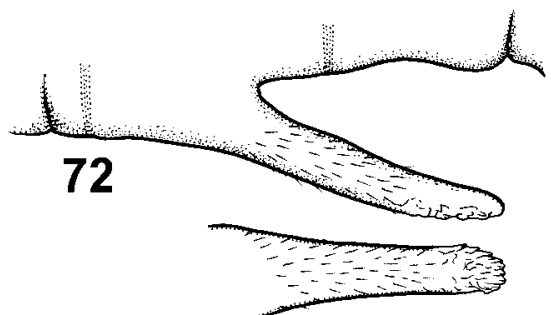

73
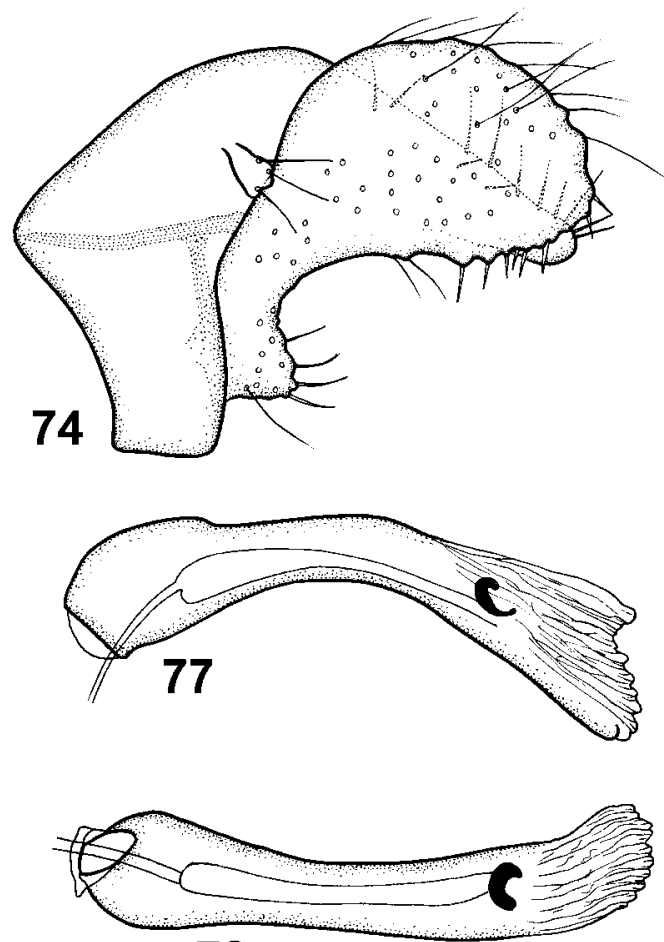

78
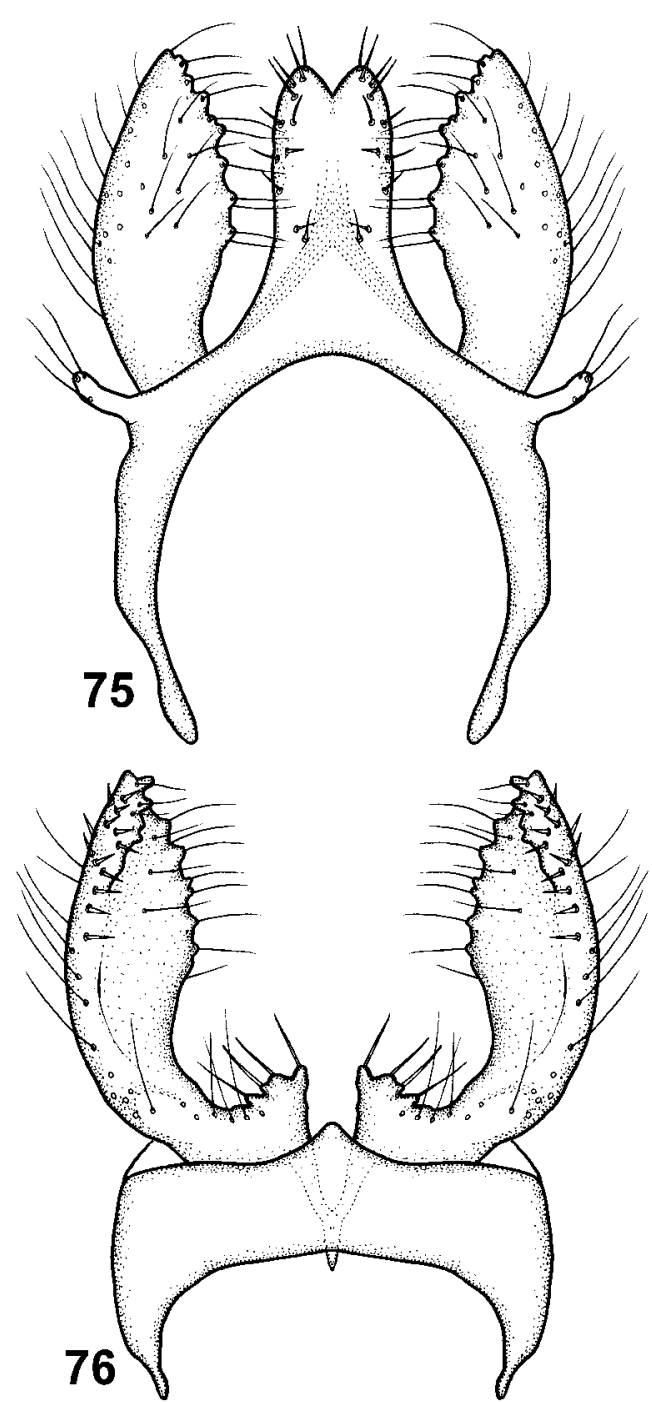

FIGURES 72-78. Helicopsyche circulata, new species, holotype. 72-sternum VI process, lateral; 73 — sternum VI process, ventral; 74—male genitalia, lateral; 75—male genitalia, dorsal; 76male genitalia, ventral; 77-phallus, lateral; 78 - phallus, ventral.

Male genitalia (Fig. 74-78). Segment IX, in lateral view (Fig. 74), with anterior lobe triangular, oriented anteriad and located midlaterally on segment; anterodorsal margin nearly straight, anteroventral margin concave; in dorsal view (Fig. 75), with inner margin narrowly ellipsoid; in ventral view (Fig. 76), with pointed posterior process; lateral apodeme present as anteriorly oriented, slightly curving line (Fig. 74) reaching anterior margin; sub-marginal line absent; tergal transverse apodeme absent; sternal transverse apodeme short. Segment X, in lateral view (Fig. 74), oriented posteroventrad, nearly straight; narrowing along its length toward rounded apex; in dorsal view (Fig. 75), narrow, 
with sub-parallel lateral margins; apex with V-shaped notch (Fig. 75); with about 11 pairs of about equally long megasetae in longitudinal group starting at proximal half on segment. Superior appendage (Fig. 74) club-shaped in lateral view, parallel-sided in dorsal view (Fig. 74, 75); oriented laterally (Fig. 75). Primary branch of gonocoxite, in lateral view (Fig. 74), widely club-shaped, with slightly undulate dorsal margin; apex rounded in lateral and dorsal views (Fig. 74, 75); central part of primary branch about as wide as height of central part of tergum X (Fig. 74); anterodorsal margin nearly straight, smooth; posteroventral margin slightly convex, undulated; basimesal lobe short, rounded in lateral view (Fig. 74); in ventral view, sharply triangular with setal bases produced posteriorly (Fig. 76); with nearly straight and parallel-sided, smooth median margins; with about 4 long megasetae on apical margin; basal plate not visible in lateral view (Fig. 74); in ventral view (Fig. 76), strongly pointing anteriorly. Phallus, in lateral view (Fig. 77), generally slender, smoothly bent ventrad along its length, dorsal margin sigmoid along proximal 2/3; ventral margin gently concave; anterior $1 / 5$ nearly $2 \mathrm{x}$ broader than its central part (Fig. 77); in ventral view (Fig. 78), slightly narrowing toward midlength; phallobase present; endotheca weakly produced (Fig. 77); sperm channel divided into thick posterior and slender anterior parts; sclerotized posteroventral part narrow (Fig. 77).

Holotype male: VENEZUELA: Aragua: $1 \mathrm{~km}$ E Estación Biológica Rancho Grande, $10.352^{\circ} \mathrm{N}, 67.680^{\circ} \mathrm{W}, 1100 \mathrm{~m}, 27.1 .1994$, Holzenthal, Cressa, Gutic (UMSP000022205) (UMSP, pinned).

Paratype: same data as holotype - 1 male (UMSP, pinned).

Distribution. Venezuela (Aragua).

Etymology. The specific epithet, circulata, is derived from the Greek kirkos, ring, and the suffix atus, provided with, referring to the circular shape of the gonocoxite. The name is to be treated as a noun in apposition.

\section{Helicopsyche (Feropsyche) perija, new species} Fig. 79-85, 88

This new species is similar to $H$. circulata and $H$. planorboides and can be separated from those species based on characters discussed in the diagnosis of $H$. circulata.

Male. Head: Antennal scape slightly longer than eye diameter. Maxillary palp segments equally long, as long as eye diameter. Cephalic warts oval, about half as long as eye diameter; with pale grey and dark grey setae, some dark brown setae near lateral margins. Forewing pale golden grey, length 3.1-3.9 mm. Sternum VI process (Fig. 79, 80) 2/5 its segment length, apparently smooth; in lateral view (Fig. 79), slightly curving posteriorly, tubular, except narrowing at apex; in ventral view (Fig. 80), parallel-sided; distally with numerous ventral subapical lamellae and apical, minute spines (Fig. 80). 

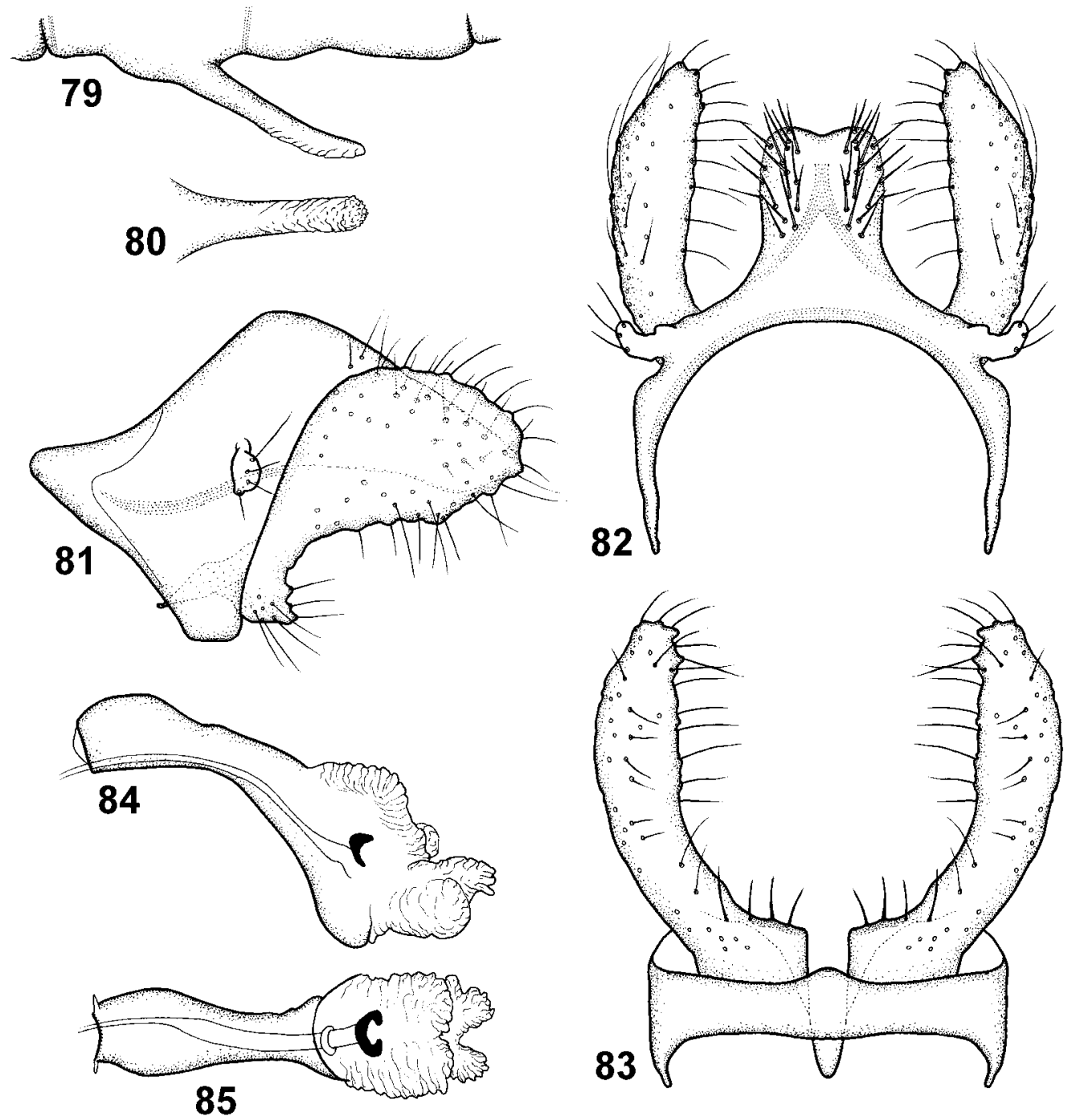

FIGURES 79-85. Helicopsyche perija, new species, holotype. 79-sternum VI process, lateral; 80—sternum VI process, ventral; 81-male genitalia, lateral; 82-male genitalia, dorsal; 83-male genitalia, ventral; 84-phallus, lateral; 85-phallus, ventral.

Male genitalia (Fig. 81-85). Segment IX, in lateral view (Fig. 81), with anterior lobe sharply triangular, oriented anterodorsad and located ventrolaterally on segment; anterodorsal margin concave, anteroventral margin shallowly concave; in dorsal view (Fig. 82), with inner margin widely ellipsoid; in ventral view (Fig. 83), with rounded posterior process; lateral apodeme sigmoid, pointing toward anterior apex of segment, fading before sub-marginal line (Fig. 81); sub-marginal line well developed, strongly convex anteriorly; transverse apodemes absent. Segment X, in lateral view (Fig. 81), oriented posteroventrad, nearly straight; narrowing along its length toward rounded apex; in dorsal view (Fig. 82), wide, with sub-parallel lateral margins; apex with wide, V-shaped notch (Fig. 82); 
with about 17 pairs of about equally long megasetae in longitudinal group starting at proximal half on segment. Superior appendage (Fig. 81) tubular; oriented ventrolaterad (Fig. 81, 82). Primary branch of gonocoxite, in lateral view (Fig. 81), widely club-shaped, with slightly undulate dorsal margin; apex rounded in lateral and dorsal views (Fig. 81, 82); central part of primary branch about as wide as height of central part of tergum X (Fig. 81); anterodorsal margin nearly straight, smooth; posteroventral margin slightly convex, undulated; basimesal lobe short, somewhat pointed in lateral view (Fig. 81); in ventral view, with about right-angled median corner, with weakly produced posterior setal bases (Fig. 83); with nearly straight and parallel-sided, smooth median margins; with about 3 long megasetae on apical margin; basal plate, in lateral view (Fig. 81), tapering toward apex; in ventral view (Fig. 83), strongly anteriorly rounded. Phallus, in lateral view (Fig. 84 ), smoothly bent ventrad at proximal $1 / 3$, dorsal margin sigmoid along proximal $2 / 3$; ventral margin gently curving ventrally at midlength; anterior $1 / 5$ nearly $2 \mathrm{x}$ broader than its central part (Fig. 84); in ventral view (Fig. 85), narrowing toward midlength; phallobase present; endotheca produced into dorsal lobe (Fig. 84); sperm channel apparently undivided; sclerotized posteroventral part wide (Fig. 84).

Holotype male: VENEZUELA: Táchira: trib. to Río El Valle, 3.8 km SE El Zumbador, $7^{\circ} 57.411^{\prime} \mathrm{N}, 7^{\circ} 04.394^{\prime} \mathrm{W}, 2730$ m, 21.iv.1995, Holzenthal, Cressa, Rincón (UMSP000022197) (UMSP, pinned).

Paratype: VENEZUELA: Zulia: Parque Nacional Perijá, Río Negro in Toromo, $10.051^{\circ} \mathrm{N}, 72.712^{\circ} \mathrm{W}, 360 \mathrm{~m}, 15.1 .1994$, Holzenthal, Cressa, Rincón - 1 male (UMSP, pinned).

Distribution. Venezuela (Táchira, Zulia).

Etymology. The name perija, is derived from the type locality, Parque Nacional Perijá. The name is to be treated as a noun in apposition.

\section{NEW DISTRIBUTION RECORDS OF VENEZUELAN HELICOPSYCHE (FEROPSYCHE)}

\section{Helicopsyche (Feropsyche) angulata Flint}

Fig. 87

VENEZUELA: Falcón: Parque Nacional Sierra de San Luis, Cataratas del Río Hueque, $11^{\circ} 10.708^{\prime} \mathrm{N}, 69^{\circ} 33.732^{\prime} \mathrm{W}, 583$ m, 6.vi.2001, Holzenthal, Blahnik, Paprocki \& Cressa 9 males, 39 females (UMSP, pinned); Parque Nacional Cueva de la Quebrada del Toro, Quebrada del Toro, $10^{\circ} 49.581^{\prime} \mathrm{N}, 69^{\circ} 07.990^{\prime} \mathrm{W}, 530 \mathrm{~m}, 11 . v i .2001$, Holzenthal, Blahnik, Paprocki \& Cressa - 6 males (UMSP, pinned); Río Mitare near San Luis, $11^{\circ} 07.930$ 'N, 69³9.184'W, 589 m, 7.vi.2001, Holzenthal, Blahnik, Paprocki \& Cressa -3 males, 5 females (UMSP, pinned). Guárico: Parque Nacional Guatopo, Queb Guatopo, $0.5 \mathrm{~km} \mathrm{~N}$ Estación La Colina, $600 \mathrm{~m}, 10.014^{\circ} \mathrm{N}, 66.363^{\circ} \mathrm{W}, 22.1 .1994$, Holzenthal, Cressa \& Rincón - 1 male, 6 females (UMSP, pinned). Lara: Quebrada Los Frailes, $8.3 \mathrm{~km}$ from San 
Pedro, 948.358'N, 7005.297'W, 1892 m, 23.vi.2001, Holzenthal, Blahnik, Paprocki \& Cressa - 14 males (UMSP, pinned); Parque Nacional Terepaima, Río Auro near Sabana Alta, $9^{\circ} 44.740 ' \mathrm{~N}, 69^{\circ} 16.614^{\prime} \mathrm{W}, 480 \mathrm{~m}, 16 . v i .2001$, Holzenthal, Blahnik, Paprocki \& Cressa - 1 male, 1 female (UMSP, pinned). Sucre: Río Cocollar, $1.5 \mathrm{~km}$ SE Las Piedras de Cocollar, $10^{\circ} 09.617^{\prime} \mathrm{N}, 63^{\circ} 47.605^{\prime} \mathrm{W}, 810 \mathrm{~m}, 7-8 . i v .1995$, Holzenthal \& Flint -5 males 13 females (UMSP, pinned); Quebrada Zapateral, $1.5 \mathrm{~km}$ SE Las Piedras de Cocollar, $10^{\circ} 09.753^{\prime} \mathrm{N}, 63^{\circ} 47.587^{\prime} \mathrm{W}, 810 \mathrm{~m}$, 9.iv.1995, Holzenthal \& Flint -3 males, 4 females (NRM, pinned).

\section{Helicopsyche (Feropsyche) breviterga Flint}

Fig. 90

VENEZUELA: Lara: Parque Nacional Dinira, Quebrada Las Pinetas, 946.311'N, 7001.749’ W, 1889 m, 22.vi.2001, Holzenthal, Blahnik, Paprocki, Cressa -2 males, 2 females (UMSP, pinned), 1 male, 1 female (NRM, pinned).

\section{Helicopsyche (Feropsyche) extensa Ross}

Fig. 86

VENEZUELA: Guárico: Parque Nacional Guatopo, Quebrada Guatopo, 0.5 km N Estación La Colina, $10.014^{\circ} \mathrm{N}, 66.363^{\circ} \mathrm{W}, 600$ m, 55.i.1994, Holzenthal, Cressa \& Rincón 1 male, 1 female (UMSP, pinned).

\section{Helicopsyche (Feropsyche) fistulata Flint}

Fig. 88

VENEZUELA: Barinas: 22 km NW Barinitas, 24.ii.1976, C.M. \& O.S. Flint, Jr. - 1 male paratype (NMNH, pinned). Mérida: Río Montalban, Rt. 4, 19 km W Merida, 20.ii.1976, C.M. \& O.S. Flint, Jr. — 2 males (NMNH, pinned); La Pedregosa, Merida, 21.ii.1976, C.M. \& O.S. Flint, Jr. — 2 males (NMNH, pinned); Quebrada La Cuesta, 5 km N Mérida, $8^{\circ} 39.142^{\prime} \mathrm{N}, 71^{\circ} 07.885^{\prime} \mathrm{W}, 2010$ m, 27.iv.1995, Holzenthal, Cressa \& Gutic 1 male, 4 females (UMSP, pinned); Río La González, road between Mérida \& Jaji, $8^{\circ} 35.090^{\prime} \mathrm{N}, 71^{\circ} 17.974^{\prime} \mathrm{W}, 1870$ m, 25.iv.1995, Holzenthal, Cressa \& Gutic - 1 female (UMSP, pinned). Táchira: Quebrada La Honda, $10 \mathrm{~km}$ E La Grita, $8^{\circ} 08.871^{\prime} \mathrm{N}$, 71 ${ }^{\circ} 56.027^{\prime} \mathrm{W}, 2300 \mathrm{~m}, 23 . i v .1995$, Holzenthal, Cressa \& Gutic -1 female (UMSP, pinned). Trujillo: Quebrada Potrerito, $7.5 \mathrm{~km} \mathrm{NE}$ Boconó, $9^{\circ} 16.435^{\prime} \mathrm{N}, 70^{\circ} 13.102^{\prime} \mathrm{W}$, 1530 m, 29-30.iv.1995, Holzenthal, Cressa \& Gutic — 1 male, 4 females (UMSP, pinned). 
VENEZUELA: Falcón: Quebrada El Charo at cataratas, $10^{\circ} 46.771^{\prime} \mathrm{N}, 6^{\circ} 12.174^{\prime} \mathrm{W}$, 425 m, 12.vi.2001, Holzenthal, Blahnik, Paprocki \& Cressa - 7 males, 15 females (UMSP, pinned), 2 males, 2 females (NRM, pinned); Parque Nacional Cueva de la Quebrada del Toro, Quebrada del Toro, 1049.581'N, 6907.990'W, 530 m, 11.vi.2001, Holzenthal, Blahnik, Paprocki \& Cressa - 1 male (UMSP, pinned). Lara: Parque Nacional Terepaima, Quebrada San Antonio, 951.754'N, 69¹3.098'W, 631 m, 17.vi.2001, Holzenthal, Blahnik, Paprocki \& Cressa -7 males, 6 females (UMSP, pinned); Quebrada Los Frailes, 8.3 km from San Pedro, 948.358’ N, 7005.297’W, 1892 m, 23.vi.2001 [Holzenthal, Blahnik, Paprocki \& Cressa -7 males (UMSP, pinned).

Remarks: The 7 males collected from Quebrada Los Frailes are somewhat larger than the other specimens, but otherwise identical in genitalia, perhaps except for the slightly wider primary branch of the gonocoxite. However, we consider the specimens to be conspecific with $H$. grenadensis.

\section{Helicopsyche (Feropsyche) maculisternum Botosaneanu} Fig. 88

VENEZUELA: Sucre: Parque Nacional Peninsula de Paria, Uquire, Río La Viuda, $10^{\circ} 42.830$ 'N, $61^{\circ} 57.661^{\prime} \mathrm{W}$, el. 15 m, 30.iii-1.iv.1995, Holzenthal, Flint \& Cressa - 1 male (NMNH, alcohol).

\section{Helicopsyche (Feropsyche) merida Botosaneanu \& Flint} Fig. 90

VENEZUELA: Barinas: Parque Nacional Sierra Nevada, Río Sinigüis at "Las Arangueres”, $8^{\circ} 33.85^{\prime} \mathrm{N}, 70^{\circ} 56.32^{\prime} \mathrm{W}, 2880 \mathrm{~m}, 13.1 i i .1997$, Holzenthal - 3 males (UMSP, pinned). Merida: $11 \mathrm{~km}$ SE Apartaderos, 23.ii.1976, Flint - male holotype (NMNH, pinned); Cord. Merida, near Merida, Paramo Laguna Negra, brook, $500 \mathrm{~m}$ from source, 3500 m, 4.x.1975, Bzibziak — 1 pharate male (NMNH, alcohol).

\section{Helicopsyche (Feropsyche) monda Flint}

Fig. 87

VENEZUELA: Amazonas: Puerto Ayacucho (40 km S) El Tobogán, Caño Coromoto, 24.i.1989, P.J. Spangler, R.A.Faitoute \& C.B.Barr - 1 male (NMNH, pinned). 
Fig. 87

VENEZUELA: Aragua: Ocumare, 19-20.ii.1969, P. \& P. Spangler - 4 males, 2 females (NMNH alcohol).

\section{Helicopsyche (Feropsyche) vergelana Ross}

Fig. 86

VENEZUELA: Amazonas: Agua Blanca, $0^{\circ} 49^{\prime} \mathrm{N}, 66^{\circ} 08^{\prime} \mathrm{W}$, Cerro d.1. Neblina, $160 \mathrm{~m}$, 20-21.iii.1984, O.S. Flint, Jr. \& J. Louton - 7 males, 20 females (NMNH, alcohol), 1 male (NMNH, pinned). Aragua: Río El Limon, fish hatchery, Maracay, 22-23.x.1974, Weibezahn -1 male (NMNH, alcohol). Barinas: Pte. Parangula, $8 \mathrm{~km} \mathrm{~S}$ Barinitas, 18.ii.1976, C.M. \& O.S. Flint, Jr. - 6 males, 6 females (NMNH, alcohol); same -2 males (NMNH, pinned). Bolívar: Puente Yocoima 2, 19 km N Upata, 13.ii.1976, C.M. \& O.S. Flint, Jr. - 1 male (NMNH, pinned). Falcón: Parque Nacional Cueva de la Quebrada del Toro, Quebrada del Toro, $10^{\circ} 49.581^{\prime} \mathrm{N}, 69^{\circ} 07.990^{\prime} \mathrm{W}, 530 \mathrm{~m}, 11 . v i .2001$, Holzenthal, Blahnik, Paprocki \& Cressa - 1 male (UMSP, pinned). Isla de Margarita: Toma de agua de Encañado, 13.vii.1936, Hummelinck — male holotype of H. margaritensis (ZMUA, slide). Lara: Parque Nacional Terepaima, Río Sarare nr. Sarare, 949.036'N, 69¹1.596'W, 357 m, 15.vi.2001, Holzenthal, Blahnik, Paprocki \& Cressa 3 males, 7 females (UMSP, pinned). Maracay: Río El Limón, fish hatchery, 1920.v.1975, F.H. Weibezahn -1 male (NMNH alcohol). Sucre: Parque Nacional Peninsula de Paria, Uquire, Río La Viuda, 1042.830’'N, 6157.661'W, 15 m, 30.iii-1.iv.1995, Holzenthal, Flint \& Cressa - 1 male (NMNH, pinned); Qebrada Zapateral, $1.5 \mathrm{~km}$ SE Las Piedras de Cocollar, $10^{\circ} 09.753^{\prime} \mathrm{N}, 63^{\circ} 47.587^{\prime} \mathrm{W}, 810 \mathrm{~m}$, 9.iv.1995, Holzenthal \& Flint 1 male, 1 female (NRM, pinned); Parque Nacional Peninsula de Paria, Puerto Viejo, Río Puerto Viejo, $10^{\circ} 43.137^{\prime} \mathrm{N}, 62^{\circ} 28.743$ 'W, 15 m, 2.iv.1995, Holzenthal, Flint \& Cressa 5 females (UMSP, pinned); Peninsula de Paria, Puerto Viejo, "Rio el Pozo", 1043.073'N, $62^{\circ} 28.569^{\prime} \mathrm{W}, 20 \mathrm{~m}, 3 . i v .1995$, Holzenthal, Flint \& Cressa -2 females (UMSP, pinned); Peninsula de Paria, Santa Isabel, Río Santa Isabel, 1044.294'N, 62³8.954’W, 20 m, 4.iv.1995, Holzenthal, Flint \& Cressa -5 females (UMSP, pinned). Zulia: Los Angeles del Tucuco, 15-16.iv.1981, A.S. Menke \& L. Hollenberg — 2 males (NMNH, pinned).

\section{Helicopsyche (Feropsyche) woytkowskii Ross}

Fig. 89

VENEZUELA: Lara: Parque Nacional Dinira, Quebrada Buenos Aires, 9³6.407'N, 7004.178'W, 1850 m, 18-19.vi.2001, Holzenthal, Blahnik, Paprocki \& Cressa - 29 
males, 34 females (UMSP, pinned), 2 males, 2 females (NRM, pinned); Quebrada Los Frailes, $8.3 \mathrm{~km}$ from San Pedro, 948.358'N, 7005.297’ W, $1892 \mathrm{~m}$, 23.vi.2001,

Holzenthal, Blahnik, Paprocki \& Cressa - 5 males (UMSP, pinned).

\section{Key to males of Venezuelan Helicopsyche (Feropsyche)}

(The species H. colombiensis, H. scalaris and H. thelidomus are omitted from the key because no male material exists.)

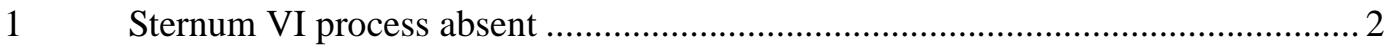

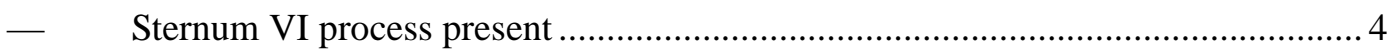

2(1) Gonocoxite, in lateral view, both uniformly wide and nearly straight along its length (Fig. 62); tergum X with about 12 megasetaeHelicopsyche laneblina $\mathrm{n}$. sp.

- Gonocoxite, in lateral view, curved posteriorly (Fig. 67) or if nearly straight narrowing at midlength (Fig. 36); tergum $X$ with about 9 megasetae

3(2) Gonocoxite, in lateral view, narrowing at midlength (Fig. 36); gonocoxite at midlength expanded mesally into wide process bearing 2 minute megasetae at apex (Fig. 37); basimesal lobe produced posteriorly (Fig. 38); tergum X apically pointed (Fig. 37)

Helicopsyche tachira $\mathrm{n}$. sp.

- Gonocoxite, in lateral view, nearly uniformly wide (Fig. 67); gonocoxite concave mesally; basimesal lobe forming triangular plate (Fig. 69); tergum $\mathrm{X}$ apically incised (Fig. 68)

Helicopsyche linabena $\mathrm{n}$. sp.

4(1) Gonocoxite boomerang-shaped, generally narrow along its length

Helicopsyche vergelana Ross

- Gonocoxite of different shape, generally wide along its length ............................. 5

5(4) Gonocoxite divided into dorsal and posterior branches ......................................... 6

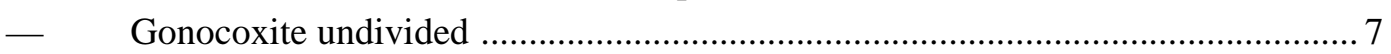

6(5) Dorsal branch of gonocoxite shorter than width of posterior branch

Helicopsyche extensa Ross

- Dorsal branch of gonocoxite longer than width of posterior branch

Helicopsyche angulata Flint

7(5) Gonocoxite distally oval or circular (Fig. 74, 81) ............................................. 8

- Gonocoxite distally rectangular, triangular or club-shaped ................................. 9

8(7) Sternum VI process longer than half its segment length (Fig. 72); segment IX, in lateral view, slightly widely produced anteriorly (Fig. 74); tergum X with approximately 11 dorsal setae (Fig. 82); in dorsal view, $\mathrm{X}$ tergum narrow along its length (Fig. 75)

Helicopsyche circulata $\mathrm{n}$. sp.

- $\quad$ Sternum VI process shorter than half its segment length (Fig. 79); segment IX, in lateral view, strongly narrowly produced anteriorly (Fig. 81); tergum $\mathrm{X}$ with approximately 16 dorsal setae (Fig. 82); in dorsal view, tergum $\mathrm{X}$ wide along its length (Fig. 82) Helicopsyche perija $\mathrm{n}$. sp. 
Helicopsyche selanderi Ross

- Gonocoxite dorsally hyperboloid (Fig. 3, 24) 10

10 (9) Gonocoxite incision between primary branch and basimesal lobe weak or absent (Fig. 19) 11

- Gonocoxite with well developed incision between primary branch and basimesal lobe (Fig. 5, 12, 26)

11(10) Gonocoxite basimesal lobe without megasetae Helicopsyche monda Flint

- Gonocoxite basimesal lobe with megasetae 12

12(11) Gonocoxite basimesal lobe triangular.. Helicopsyche merida Botosaneanu \& Flint

- Gonocoxite basimesal lobe nearly straight or rounded (Fig. 19)...................... 13

13(12) Gonocoxite, in lateral view, sub-rectangular .......... Helicopsyche breviterga Flint

- Gonocoxite, in lateral view, club-shaped (Fig. 17).. Helicopsyche succincta n. sp.

14(10) Gonocoxite basimesal lobe triangular (Fig. 5, 12, 33) ................................ 15

- Gonocoxite basimesal lobe tubular (Fig. 26, 45, 52, 59)............................ 21

15(14) Gonocoxitebasimesallobenearlycompletely hidden by primary branchin lateral view 16

- Gonocoxite basimesal lobe completely visible in lateral view.......................... 18

16(15) Sternum VI process about $1 / 2$ the length of segment VI.

Helicopsyche maculisternum Botosaneanu

- Sternum VI process about $1 / 3$ the length of segment VI 17

17(16) Tergum $X$ strongly convex Helicopsyche woytkowskii Ross

- Tergum X slightly convex Helicopsyche fistulata Flint

18(15) Gonocoxite basimesal lobe long (Fig. 33); tergum X with setae on dorsal process (Fig. 31) Helicopsyche auroa n. sp.

- Gonocoxite basimesal lobe short (Fig. 5, 12); tergum X with no setose dorsal process (Fig. 3, 10)

19(18) Basal plate exceeds anterior part of anterior lobe of segment IX (Fig. 3); gonocoxite with anterodorsal and posteroventral margins nearly parallel (Fig. 3)....

Helicopsyche sucrensis n. sp.

- Basal plate shorter than anterior part of anterior lobe of segment IX (Fig. 10); gonocoxite with anterodorsal and posteroventral margins diverging (Fig. 10) .... 20

20(19) Tergum X widely incised apically (Fig. 11); gonocoxite posteroventral margin with a single, slightly produced setal bases (Fig. 10); tergum X concave (Fig. 10).

Helicopsyche disjuncta n. sp.

- Tergum X not incised apically; gonocoxite posteroventral margin with 3 large, produced setal bases; tergum X convex Helicopsyche grenadensis Flint \& Sykora

21(14) Sternum VI process broad in ventral view (Fig. 49).

Helicopsyche venezuelensis $\mathrm{n} . \mathrm{sp}$.

- Sternum VI process narrow in ventral view (Fig. 23, 42, 56) 22 
22(21) Tergum X slender in dorsal view, apically incised (Fig. 44)

- Tergum X wide in dorsal view, apically rounded (Fig. 25, 58)

23(22) Gonocoxite with posteroventral margin concave (Fig. 24)

Helicopsyche camuriensis n. sp.

- Gonocoxite with posteroventral margin nearly straight (Fig. 57)

Helicopsyche lara $\mathrm{n} . \mathrm{sp}$.

\section{Acknowledgments}

We are indebted to Dr. Oliver S. Flint, Jr. (NMNH) for kindly making additional Venezuelan Helicopsyche material available for this study. We are especially indebted to Dr. Claudia Cressa, Universidad Central de Venezuela, for her assistance to the junior author during his field research in Venezuela. We thank Dr. Roger Blahnik, University of Minnesota, for his preliminary assessment of the UMSP material and its curation. This material is based on work supported by the National Science Foundation under Grant Nos. 9971885 and 0117772. Additional support was provided by the University of Minnesota Insect Collection under project AES MIN-17-015. This support is gratefully acknowledged.

\section{References}

Blahnik, R.J. (2004) New species of Chimarrhodella from Venezuela and Ecuador (Trichoptera: Philopotamidae). Zootaxa, 551, 1-7.

Blahnik, R.J. \& Holzenthal, R.W. (2004) Collection and curation of Trichoptera, with an emphasis on pinned material. Nectopsyche, Neotropical Trichoptera Newsletter, 1, 8-20. Available from http://www.entomology.umn.edu/museum/links/news.html (accessed 28 June 2004).

Flint O.S., Jr., Holzenthal, R.W. \& Harris, S.C. (1999) Catalog of the Neotropical Caddisflies (Insecta: Trichoptera). Ohio Biological Survey, Columbus, Ohio, 239 pp.

Harris, S.C. \& Flint, O.S., Jr. (2002) New Alisotrichia (Trichoptera: Hydroptilidae) from Central and South America and the Greater Antilles. Proceedings of the Entomological Society of Washington, 104, 195-210.

Harris, S.C., Holzenthal, R.W. \& Flint, O.S., Jr. (2002a) Review of the Neotropical genus Bredinia (Trichoptera: Hydroptilidae: Stactobiini). Annals of the Carnegie Museum, 71, 13-45.

Harris, S.C., Flint, O.S., Jr. \& Holzenthal, R.W. (2002b) Two new genera of Hydroptilidae from the Neotropics (Trichoptera: Hydroptilidae: Stactobiini). Journal of the New York Entomological Society, 110, 49-64.

Holzenthal, R.W. \& Cressa, C. (2003) The Trichoptera, Caddisflies, of Venezuela: three new species and records of Atopsyche Banks (Hydrobiosidae). Studies on Neotropical Fauna and Environment, 37, 133-143.

Holzenthal, R.W. \& Andersen, T. The caddisfly genus Triaenodes in the Neotropics (Trichoptera: Leptoceridae). Zootaxa, 511, 1-80.

Johanson, K.A. (1998). Phylogenetic and biogeographic analysis of the family Helicopsychidae (Insecta: Trichoptera). Entomologica Scandinavica, Supplement 53, 1-172. 
Johanson, K.A. (2002) Systematic revision of American Helicopsyche of the subgenus Feropsyche (Trichoptera: Helicopsychidae). Insect Systematics and Evolution Supplement, 60, 1-147.

Johanson, K.A. (2003a) The sister species of Jamaican Helicopsyche kingstona sp.n., is Mexican H. villegasi Denning \& Blickle (Trichoptera, Helicopsychidae). Tijdschrift voor Entomologie, 146, 33-37.

Johanson, K.A. (2003b) Revision of the Neotropical caddisfly subgenus Helicopsyche (Cochliopsyche) (Trichoptera, Helicopsychidae), with descriptions of twelve new species. Insect Systematics and Evolution, 34, 381-414.

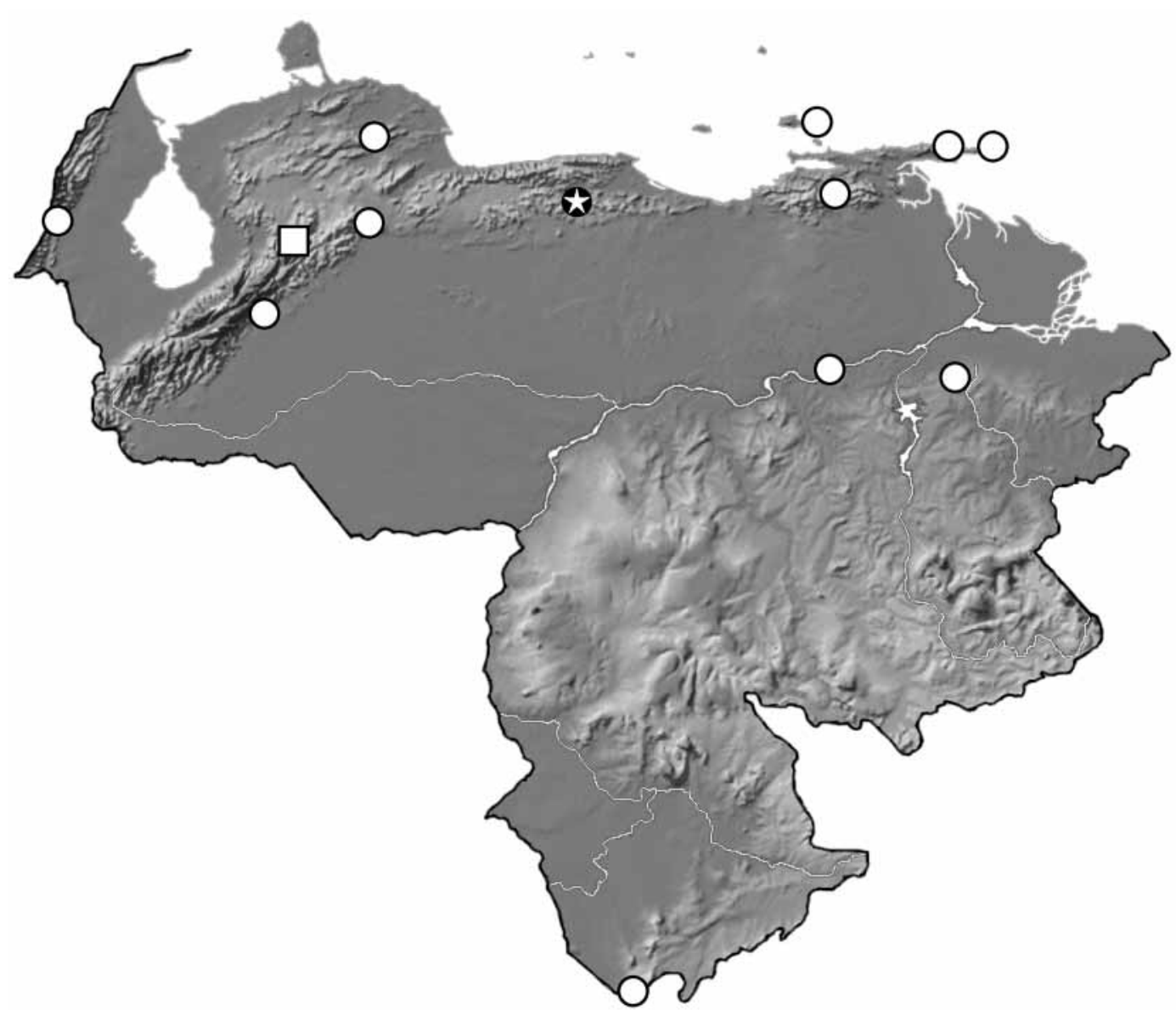

FIGURE 86. Map of Venezuela showing distributions of $H$. vergelana (circle), H. extensa (star), and H. lara (rectangle). 


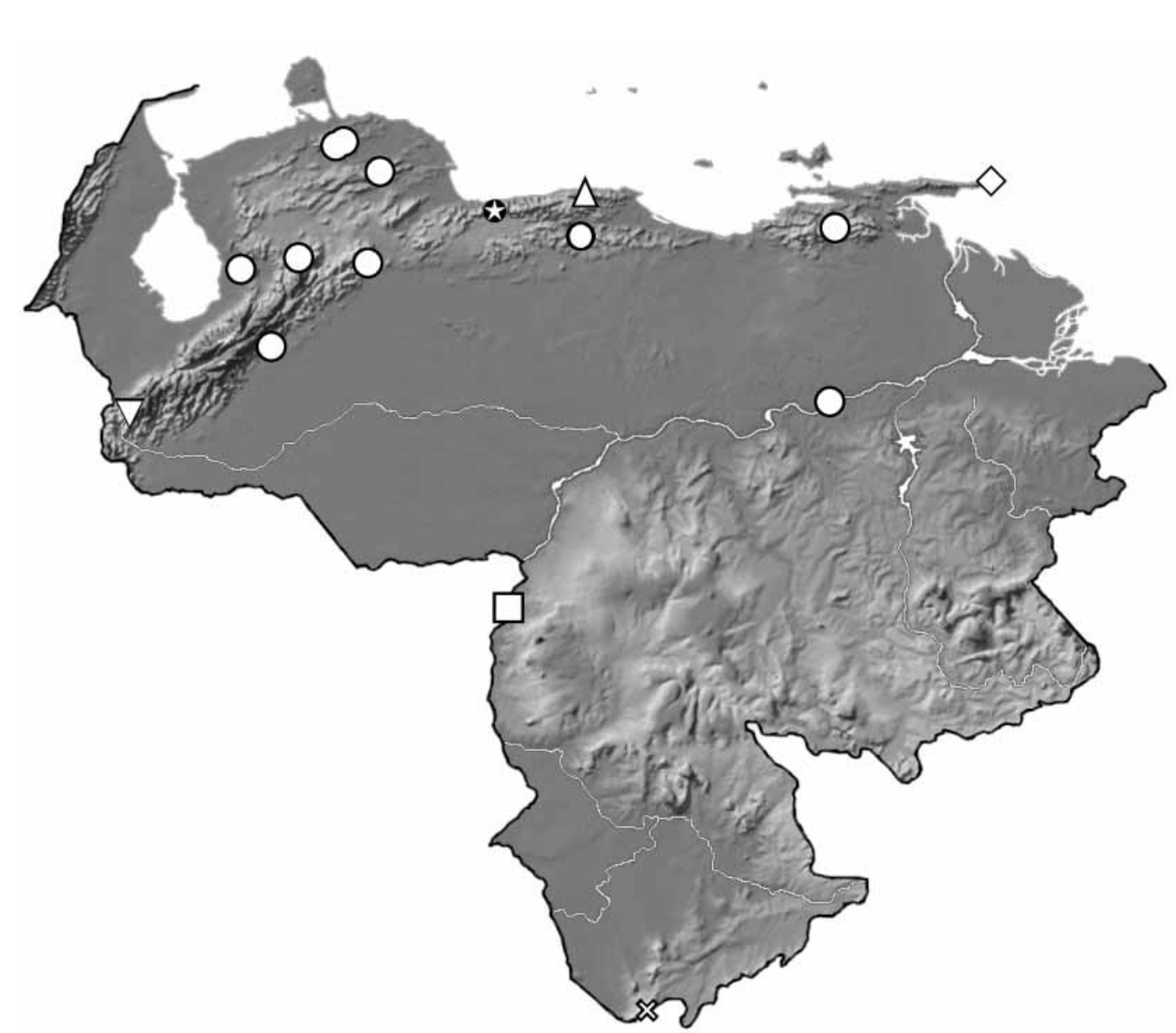

ZOOTAXA

FIGURE 87. Map of Venezuela showing distributions of $H$. angulata (circle), $H$. monda (rectangle), H. tachira (triangle down), H. disjuncta (diamond), H. linabena (cross), H. camuriensis (triangle up), and H. selanderi (star). 


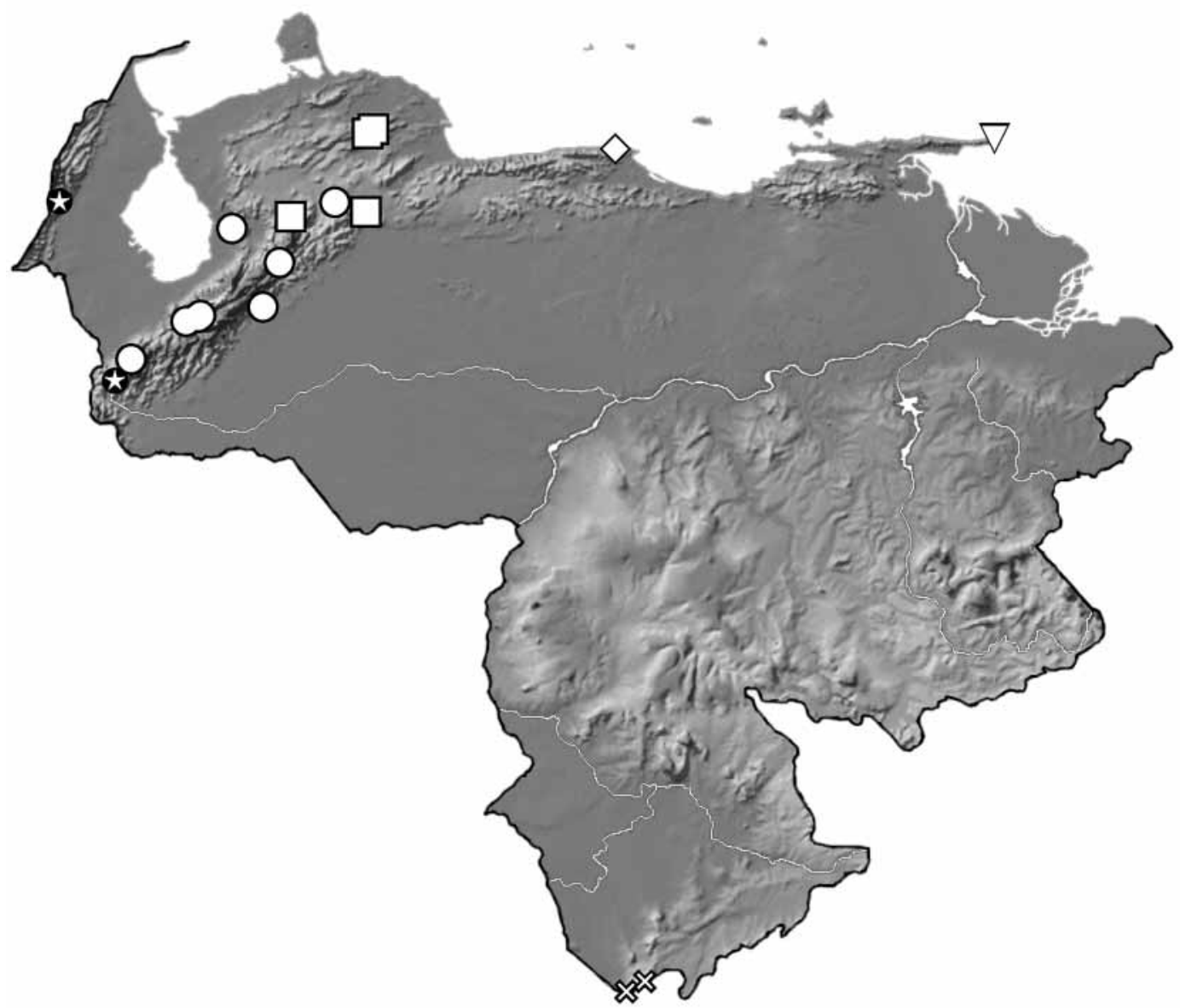

FIGURE 88. Map of Venezuela showing distributions of $H$. fistulata (circle), $H$. grenadensis (rectangles), H. maculisternum (triangle), H. venezuelensis (diamond), H. neblinensis (crosses), and $H$. perija (stars). 


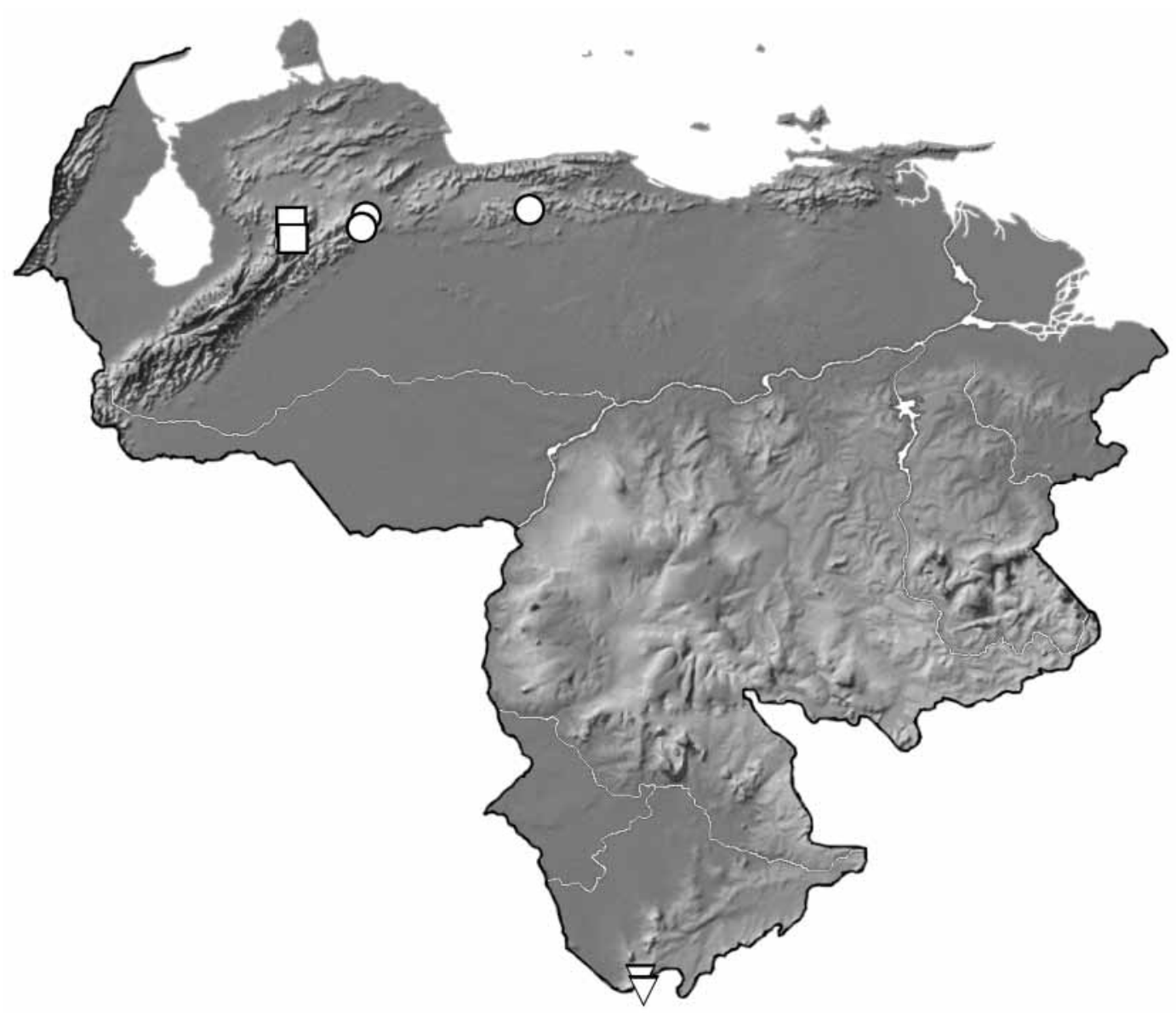

FIGURE 89. Map of Venezuela showing distributions of $H$. auroa (circle), H. woytkowskii (rectangles), and $H$. succincta (triangles). 


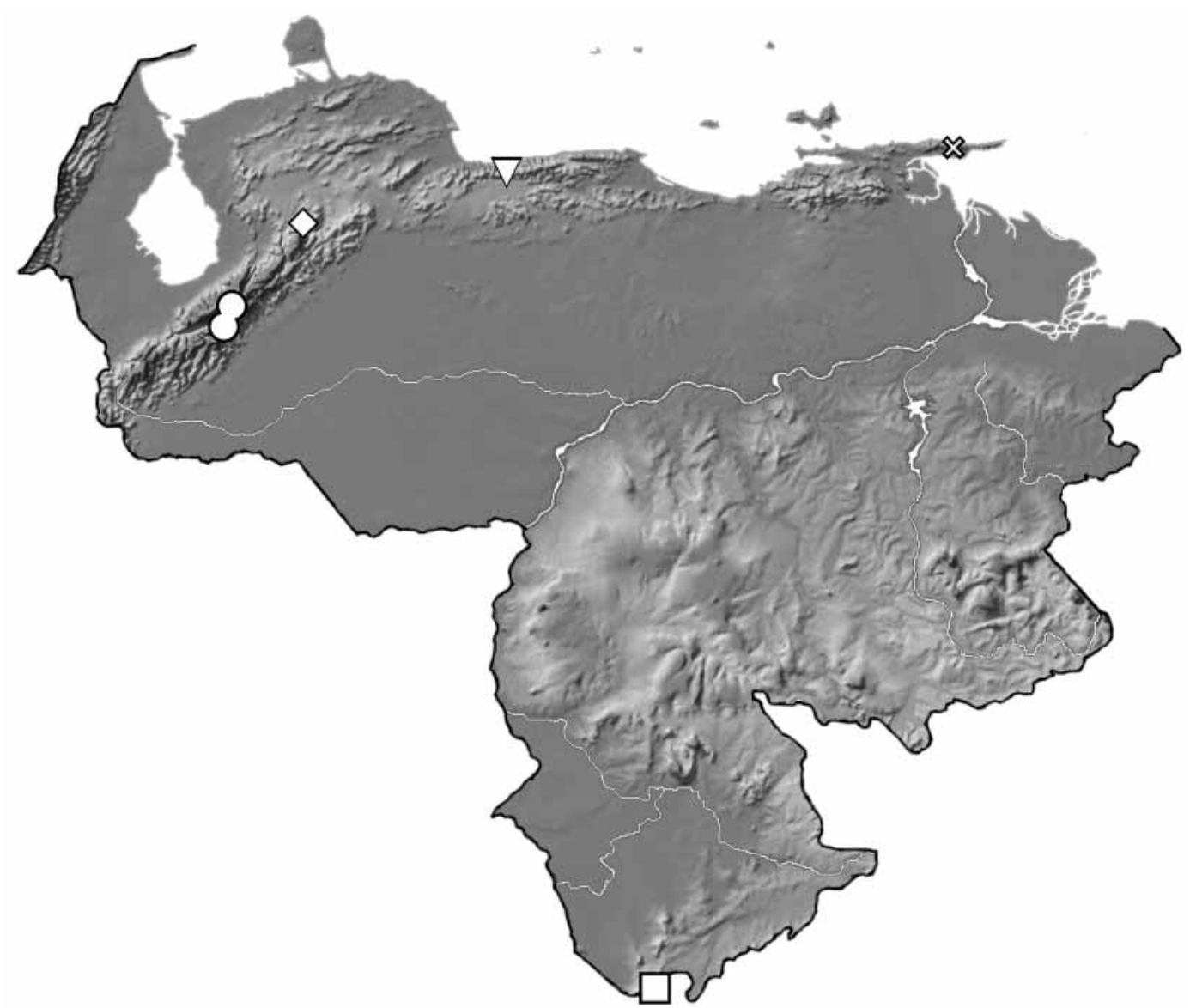

FIGURE 90. Map of Venezuela showing distributions of H. merida (circle), H. laneblina (rectangle), H. sucrensis (cross), H. breviterga (diamond), and H. circulata (triangle). 